\title{
Mice Microbiota Composition Changes by Inulin Feeding with a Long Fasting Period under a Two-Meals-Per-Day Schedule
}

\author{
Hiroyuki Sasaki ${ }^{1,2, \dagger}$, Hiroki Miyakawa ${ }^{1,+}$, Aya Watanabe ${ }^{1}$, Yuki Nakayama ${ }^{1}$, Yijin Lyu ${ }^{1}$, \\ Koki Hama ${ }^{1}$ and Shigenobu Shibata ${ }^{1, *(D)}$ \\ 1 Laboratory of Physiology and Pharmacology, School of Advanced Science and Engineering, \\ Waseda University, Shinjuku-ku, Tokyo 162-8480, Japan; hiroyuki-sasaki@asagi.waseda.jp (H.S.); \\ hgbbst-hiroki@toki.waseda.jp (H.M.); aya_watanabe7115@suou.waseda.jp (A.W.); \\ yukibecky-6991@akane.waseda.jp (Y.N.); ikin@fuji.waseda.jp (Y.L.); koby_frekoi418@ruri.waseda.jp (K.H.) \\ 2 AIST-Waseda University Computational Bio Big-Data Open Innovation Laboratory (CBBD-OIL), \\ National Institute of Advanced Industrial Science and Technology, Shinjuku-ku, Tokyo 169-8555, Japan \\ * Correspondence: shibatas@waseda.jp; Tel.: +81-3-5369-7318 \\ + These authors contributed equally to this work.
}

Received: 23 October 2019; Accepted: 14 November 2019; Published: 16 November 2019

\begin{abstract}
Water-soluble dietary fiber is known to modulate fecal microbiota. Although there are a few reports investigating the effects of fiber intake timing on metabolism, there are none on the effect of intake timing on microbiota. Therefore, in this study, we examined the timing effects of inulin-containing food on fecal microbiota. Mice were housed under conditions with a two-meals-per-day schedule, with a long fasting period in the morning and a short fasting period in the evening. Then, 10-14 days after inulin intake, cecal content and feces were collected, and cecal $\mathrm{pH}$ and short-chain fatty acids (SCFAs) were measured. The microbiome was determined using $16 \mathrm{~S}$ rDNA sequencing. Inulin feeding in the morning rather than the evening decreased the cecal $\mathrm{pH}$, increased SCFAs, and changed the microbiome composition. These data suggest that inulin is more easily digested by fecal microbiota during the active period than the inactive period. Furthermore, to confirm the effect of fasting length, mice were housed under a one-meal-per-day schedule. When the duration of fasting was equal, the difference between morning and evening nearly disappeared. Thus, our study demonstrates that consuming inulin at breakfast, which is generally after a longer fasting period, has a greater effect on the microbiota.
\end{abstract}

Keywords: microbiota; inulin; circadian rhythm; feeding timing

\section{Introduction}

In the gut of mammals, the microbiota includes 100 trillion bacteria. Disordered microbiota alteration is involved in the development of various diseases [1]. Firmicutes are bacteria related to obesity, while Bacteroidetes suppress fat accumulation in mice fed a high-fat diet (HFD) [2]. When the feces of obese mice are transplanted into germ-free mice, obesity develops [3]. Moreover, Fusobacterium, including Fusobacterium nucleatum, are increased in patients with colorectal cancer compared with healthy subjects $[4,5]$. In addition to physical illnesses, a relationship of microbiota with psychological illness has also been reported. In patients with major depression, Bacteroidetes, Proteobacteria, and Actinobacteria are significantly increased compared with healthy subjects [6]. These results suggest that intestinal bacteria are related to the development of diseases and that maintaining homeostasis of the microbiota is important for the mental and physical health of the host. 
Short-chain fatty acids (SCFAs) are produced when the microbiota ferments and degrades non-digestible food components [7]. The SCFAs lower intestinal $\mathrm{pH}$, suppress the growth of pathogenic bacteria in the gut, and function as a regulator of metabolism and immunity [8]. Among SCFAs, acetic acid is a liver energy substrate used for fat synthesis, and propionic acid is used as a material for gluconeogenesis in the liver. Butyrate promotes the induction of regulatory $\mathrm{T}$ cells in the large intestine $[9,10]$. Furthermore, SCFAs also increase insulin sensitivity in the liver and muscles through GPR43, a receptor for SCFAs in white fat, as well as increase energy efficiency [11].

The circadian rhythm, controlled by clock genes, plays an important role in daily locomotor activity rhythms and physiological events, such as the sleep-wake cycle, hormone secretion, and the sympathetic nervous system [12,13]. Clocks in peripheral tissues are regulated by the central clock in the suprachiasmatic nucleus and external cues such as food, temperature, and exercise [14-16]. It has been reported that circadian rhythms are also present in the intestinal flora and controlled by dietary composition [17-20]. Furthermore, disturbance of the circadian clock due to jet lag alters microbial populations. For example, when the stool of jet-lagged mice is transplanted into germ-free mice, the recipient mice become obese [19]. Recently, however, it has been reported that SCFAs produced by gut microbiota can synchronize the circadian clock [21].

The microbiota composition changes depending on food components. In particular, foods rich in dietary fiber have a strong effect on the microbiota and are known as prebiotics [22]. According to Gibson et al., prebiotics are defined as "nondigestible food ingredients that beneficially affect the host by selectively stimulating the growth and/or activity of one or a limited number of bacterial species already resident in the colon, and thus attempt to improve host health" [23]. Inulin is a water-soluble dietary fiber and, thus, a prebiotic. It is particularly involved in the growth of bacteria that produce lactic acid [24] and promote the absorption of minerals such as calcium and magnesium $[25,26]$.

It has been suggested that meal timing and daily eating habits may affect the development and prevention of lifestyle-related diseases such as obesity. A study by Hatori et al. demonstrates that restricted feeding in an activity period for mice without reducing calorific intake prevents metabolic diseases in mice fed a HFD [27]. Mice consuming milk fat late in the activity period have elevated hepatic fat and increased serum triglycerides and free fatty acids [28]. In addition, scheduled access to a HFD during the inactivity period increases body weight in mice compared with access during the activity period [29,30]. Moreover, in human experiments, the combination of a late dinner with a short sleep duration is associated with the risk of obesity [31]. In addition, the risk of obesity has been related to eating supper after 20:00 in the evening [32]. In recent years, it has been suggested that the influence of food on lipid metabolism is different depending on the time of food intake. In mice fed a high-fructose diet, fish oil given earlier in the activity period rather than later more effectively lowered lipids [33].

There are many reports indicating that time of food intake affects energy metabolism, but there are still relatively few reports describing the effect of eating time on microbiota. Furthermore, there are few reports on the dual effect of food type, particularly dietary fiber, and intake time on microbiota. Therefore, in the current study, we investigated whether inulin intake during the morning has a stronger effect on the microbiota than inulin intake during the evening with a two-meals-per-day schedule in mice.

\section{Materials and Methods}

\subsection{Mice}

In this study, we used eight-week-old male ICR mice (Tokyo Laboratory Animals, Tokyo, Japan). The mice were kept in a room maintained on a $12 \mathrm{~h}$ light/12 h dark (LD) cycle (lights on from 08:00 to 20:00). Zeitgeber time 0 (ZT0) was designated as lights-on time and ZT12 as lights-off time under the LD cycle. The mice were housed either in groups (five mice per cage; experiments 1 and 2) or individually (experiments 3 and 4 ) in plastic cages. The cages were maintained at a temperature of 
$22 \pm 2{ }^{\circ} \mathrm{C}$, humidity of $60 \pm 5 \%$, and light intensity of 100-150 lux. The mice were provided with a HFD containing 45\% kcal of fat (Diet 12451; Research Diets Inc., New Brunswick, NJ, USA) with cellulose (Oriental Yeast Co., Ltd., Tokyo, Japan) or inulin (Fuji FF; Fuji Nihon Seito Co., Tokyo, Japan) [34,35] and water ad libitum. This HFD is a diet used as a model for obesity, diabetes, and fatty liver in rodents [36,37]. Inulin has been reported to attenuate HFD-induced lipid metabolism and microbiota change [38]. In addition, the metabolic syndrome caused by obesity and abnormal lipid metabolism in the liver are related to microbiota change [39-41]. Therefore, we used an HFD to enhance the attenuating effects of inulin with the condition of microbiota change. The animal experiment was conducted with permission from the Committee for Animal Experimentation of the School of Science and Engineering at Waseda University (permission \# 09A11, 10A11) and in accordance with the law (No. 105) and notification (No. 6) of the Japanese government.

\subsection{Scheduled Feeding}

We prepared two types of feeding conditions. In type 1 (experiments 1 and 2), only the feeding time was controlled, while in type 2 (experiments 3 and 4), both the start time of feeding and the amount of food were controlled.

In type 1 feeding, all of the mice could approach the feed box during the permitted time. We defined the morning as ZT12-20 and the evening as ZT20-4. The mice had free access to the feed box for predetermined four-hour periods (morning meal as ZT12-16 and evening meal as ZT20-0). Throughout the remaining time, the feed box was locked. Food intake was calculated by measuring the weight of the food in the feed box at the start and end of the experiment. The total consumed food was divided by the number of mice and the number of days in the experiment. In the type 1 experiments, we housed the mice as a group to avoid the stress induced by individual housing.

In type 2 feeding, all of the mice were housed in cages containing food dispensers that released food pellets under the regulation of a timer. The mice were fed $90 \%$ of the amount of food that was consumed in experiment 1 (Figure 1c). In experiment 3, the mice were fed two meals per day at ZT12 (defined as morning) or ZT20 (defined as evening); the meal size was $1.8 \mathrm{~g}$. In experiment 4 , the mice were fed one meal per day at ZT12 (morning) or ZT20 (evening); the meal size was $3.6 \mathrm{~g}$.

We adjusted the concentration of dietary fiber so that the amount of inulin was approximately equal between experiments.

\subsection{Cecal pH Measurement}

The cecal $\mathrm{pH}$ was measured by inserting the glass tip of an electrode of a $\mathrm{pH}$ meter (pH Spear; Eutech Instruments, Vernon Hills, IL, USA) directly into the cecum.

\subsection{Measurement of SCFAs}

The SCFAs were measured via gas chromatography and flame ionization detection (Shimadzu Corp., Kyoto, Japan) as described by a previous report [42] with some modifications. A total of $0.05 \mathrm{~g}$ of cecal content was acidified with $0.05 \mathrm{~mL}$ sulfuric acid (FUJIFILM Wako Pure Chemical Corp., Osaka, Japan). Then, the SCFAs were extracted by shaking with $0.4 \mathrm{~mL}$ of diethyl ether (FUJIFILM Wako Pure Chemical Corp., Osaka, Japan) and $0.2 \mathrm{~mL}$ of ethanol (FUJIFILM Wako Pure Chemical Corp., Osaka, Japan), which was then centrifuged at 14,000 rpm at room temperature for $30 \mathrm{~s}$. A total of $1 \mu \mathrm{L}$ of the organic phase was injected into the capillary column (InertCap Pure WAX $(30 \mathrm{~m} \times 0.25 \mathrm{~mm}, \mathrm{df}=0.5 \mu \mathrm{m})$; GL Science Inc., Tokyo, Japan). The initial temperature was $80^{\circ} \mathrm{C}$, and the final temperature was $200{ }^{\circ} \mathrm{C}$. Helium was used as a carrier gas. Quantification of the samples was performed using calibration curves for acetic, lactic, propionic, and butyric acids. A standard curve for each acid was conducted for their quantitation in the samples. 


\subsection{Fecal DNA Extraction}

The fecal DNA was extracted as previously described, with some modifications [43]. About $0.2 \mathrm{~g}$ of the fecal sample was suspended in a $50 \mathrm{~mL}$ Falcon tube containing $20 \mathrm{~mL}$ PBS. The suspension was filtered through a 100- $\mu \mathrm{m}$ mesh nylon filter (Corning Inc., New York NY, USA). The debris on the filter was washed with $10 \mathrm{~mL}$ of Phosphate buffered salts (PBS). The filtrates were centrifuged at 4000 rpm for $20 \mathrm{~min}$ at $4{ }^{\circ} \mathrm{C}$, and each precipitate was then suspended with $1.5 \mathrm{~mL}$ of TE10 buffer $(10 \mathrm{mM}$ Tris-HCl (FUJIFILM Wako Pure Chemical Corp., Osaka, Japan)/10 mM ethylenediaminetetraacetic acid (EDTA) (DOJINDO, Tokyo, Japan)). The suspensions were transferred to 2-mL microtubes before being centrifuged at 10,000 rpm for five minutes at $4{ }^{\circ} \mathrm{C}$. Following this, each precipitate was suspended again with $0.8 \mathrm{~mL}$ of TE10 buffer. The DNA was extracted using $1 \mathrm{~mL}$ of PCI (Invitrogen, Carlsbad, CA, USA) and isolated with $0.1 \mathrm{~mL}$ of lysozyme (FUJIFILM Wako Pure Chemical Corp., Osaka, Japan) and $0.02 \mathrm{~mL}$ of achromopeptidase (FUJIFILM Wako Pure Chemical Corp., Osaka, Japan). The DNA was purified via treatment with RNase (Promega Corp., Madison, WI, USA), followed by precipitation with 20\% PEG solution (Tokyo Chemical Industry Co., Ltd., Tokyo, Japan). Finally, the DNA was rinsed with $70 \%$ ethanol and dissolved in $50 \mu \mathrm{L}$ TE buffer.

\subsection{S rDNA Gene Sequencing}

The $16 \mathrm{~S}$ rDNA gene sequencing was performed according to the instructions of Illumina. V3-V4 variable regions of the $16 \mathrm{~S}$ rDNA gene were amplified by PCR using the following primers:

forward primer $=5^{\prime}$-TCGTCGGCAGCGTCAGATGTGTATAAGAGACAGCCTA

CGGGNGGCWGCAG-3';

reverse primer $=5^{\prime}$-GTCTCGTGGGCTCGGAGATGTGTATAAGA

\section{GACAGGACTACHVGGGTATCTAATCC-3' .}

The PCR amplification was performed with $2.5 \mu \mathrm{L}$ microbial DNA $(5 \mathrm{ng} / \mu \mathrm{L}), 5 \mu \mathrm{L}$ of each primer $(1 \mu \mathrm{mol} / \mathrm{L})$, and $12.5 \mu \mathrm{L} 2 \times \mathrm{KAPA}$ HiFi HotStart Ready Mix (Kapa Biosystems Inc., Wilmington, MA, USA). The following PCR procedure was used: $95^{\circ} \mathrm{C}$ for three minutes, followed by 25 cycles of $95^{\circ} \mathrm{C}$ for $30 \mathrm{~s}, 55^{\circ} \mathrm{C}$ for $30 \mathrm{~s}$, and $72{ }^{\circ} \mathrm{C}$ for $30 \mathrm{~s}$. Finally, an extension was performed at $72{ }^{\circ} \mathrm{C}$ for five minutes. The Amplicon PCR products were purified using AMPure XP beads (Beckman Coulter, Inc., Brea, CA, USA), according to the manufacturer's instructions. A Nextera XT Index Kit v2 (Illumina Inc., Hayward, CA, USA) was used for the Illumina sequencing adapters and attachment of the dual indices. An index PCR was performed with 5.0 $\mu \mathrm{L}$ PCR product, $5.0 \mu \mathrm{L}$ of each of the Nextera XT Index Primers, $25 \mu \mathrm{L} 2 \times$ KAPA HiFi HotStart Ready Mix, and $10 \mu \mathrm{L}$ PCR-Grade Water. The PCR was performed via the following procedure: $95^{\circ} \mathrm{C}$ for three minutes, followed by eight cycles of $95^{\circ} \mathrm{C}$ for $30 \mathrm{~s}, 55^{\circ} \mathrm{C}$ for $30 \mathrm{~s}$, and $72{ }^{\circ} \mathrm{C}$ for $30 \mathrm{~s}$. Finally, an extension was performed at $72{ }^{\circ} \mathrm{C}$ for five minutes. The index PCR products were purified using AMPure XP beads (Beckman Coulter, Inc., Brea, CA, USA). The quality of the purifications was checked using the Agilent 2100 Bioanalyzer with a DNA1000 Kit (Agilent Technologies Inc., Santa Clara, CA, USA). Finally, the DNA library was diluted to $4 \mathrm{nmol} / \mathrm{L}$.

Then, the DNA library was sequenced using the Miseq Reagent Kit v3 (Illumina Inc.) in the Illumina Miseq $2 \times 300$ bp platform, according to the manufacturer's instructions.

\subsection{Analysis of $16 \mathrm{~S} r \mathrm{DNA}$ Gene Sequences}

The 16S rDNA sequence reads were processed by the Quantitative Insights into Microbial Ecology (QIIME) pipeline version 1.9.1 [44]. The quality-filtered sequence reads were assigned to operational taxonomic units at $97 \%$ identity with the UCLUST algorithm [45]; these reads were then compared with reference sequence collections in the Greengenes database (August 2013 version). A total of 6,680,549 reads were obtained from the 91 samples. On average, 73,412 \pm 4606 reads were obtained per sample. The taxonomy summary at the phylum to genus levels, alpha diversity such as the Simpson diversity 
index, beta diversity, and principal coordinate analysis (PCoA) were calculated and generated using QIIME. A PCoA analysis was also calculated using weighted UniFrac distances.

\subsection{Predicted Metagenomes}

In experiments 3 and 4 , the functional profiles of microbial communities were predicted by the Phylogenetic Investigation of Communities by Reconstruction of Unobserved States (PICRUSt) [46]. The functional predictions were assigned to the Kyoto Encyclopedia of Genes and Genomes (KEGG) ortholog functional profiles of microbial communities via $16 \mathrm{~S}$ sequences. We selected and examined categories related to "carbohydrate metabolism" for simplification and clarity of the analysis.

\subsection{Statistical Analysis}

The data were expressed as means \pm standard error of the mean (SEM). All statistical analyses were performed using GraphPad Prism (version 6.03, GraphPad Software Inc., San Diego, CA, USA). We checked whether the data showed a normal or non-normal distribution and equal or biased variation via the D'Agostino-Pearson test/Kolmogorov-Smirnov test and F-value test/Bartlett's test, respectively. If the data showed a normal distribution and equal variation, the statistical significance was determined by the Student's $t$-test or one-way ANOVA with a Tukey's test or two-way ANOVA with a Tukey's post-hoc analysis if the interaction was significant. If the interaction was not significant but the main effect was, Sidak's post-hoc analysis was used. If the data showed a non-normal distribution or biased variation, the statistical significance was determined by the Mann-Whitney test or Kruskal-Wallis test with a Dunn post-hoc analysis and a two-stage linear step-up procedure of the Benjamini, Krieger, and Yekutieli test for multiple comparisons. The permutational multivariate analysis of variance (PERMANOVA) was used to assess the change of the microbiota composition. The PERMANOVA was analyzed by QIIME.

\section{Results}

\subsection{Inulin Intake Changed Microbiota Composition under Both Morning and Evening Timings}

In this experiment, cellulose, an insoluble dietary fiber, was added to the HFD as a control for inulin because the dietary fiber contained in this HFD was cellulose. The amount of dietary fiber in the food was kept the same between each group. Indeed, when comparing the HFD with and without cellulose, there was no significant difference in the body weight, food intake, cecal $\mathrm{pH}$, amount of SCFAs, or microbiota composition of the mice (Figure S1). Therefore, this concentration of cellulose did not appear to affect these factors.

Some reports have suggested that inulin consumption induces changes in the microbiota composition [47-50]. Here, we divided the mice into two groups. Group 1 received cellulose and was fed an HFD with $2.5 \%$ cellulose in the morning and evening. Group 2 received inulin and was fed HFD with 2.5\% inulin in the morning and evening. The mice were housed under each condition for 10 days, after which they were sacrificed at ZT20 (four hours after the morning intake) or ZT4 (four hours after the evening intake) on days 10-11 (Figure 1a). We sampled the cecal content and feces from the rectum and measured the cecal $\mathrm{pH}$. There was no significant difference in the body weight between the two groups before sacrifice (Figure 1b), nor was there was a difference in the food intake between them (Figure 1c). There were no standard error bars in the food intake volume because of the group housing.

The cecal $\mathrm{pH}$ was significantly lower in the inulin group than in the cellulose group at both ZT20 and ZT4 (Figure 1d). The propionic acid level was significantly higher in the inulin group than in the cellulose group at ZT4, and the lactic acid level was significantly higher in the inulin group than in the cellulose group at ZT20. At ZT4, there was only a slight increase in the inulin group compared with the cellulose group. In the cellulose group, the lactic acid level was significantly different between 
ZT20 and ZT4. There were no significant differences in the acetic acid, propionic acid, and total SCFA levels between the cellulose and inulin group at either ZT20 or ZT4 (Figure 1e-i).

As the propionic and lactic acid increased and the cecal $\mathrm{pH}$ decreased, the microbiota may have changed due to inulin feeding. Therefore, we extracted $16 \mathrm{~S}$ rDNA from the mice feces and analyzed the microbiota. In the cellulose group, the values of alpha-diversity as described by the Simpson index were significantly higher at ZT4 than at ZT20. The Simpson index was significantly higher in the inulin group than in the cellulose group at ZT20, but there was no significant difference observed at ZT4 (Figure 1j). Next, we examined the differences in the changes of the relative abundance of taxa between the inulin group and cellulose group. Some of the detected bacteria are shown in Figure 2. At the phylum level, the relative abundance of Firmicutes was significantly lower in the inulin group than in the cellulose group at ZT20. However, there was no significant difference in the relative abundance of Bacteroidetes between the inulin and cellulose groups, though the levels were increased slightly in the former (Figure 2a). At the genus level, the relative abundance of Lactococcus and Streptococcus significantly decreased in the inulin group at ZT20, and the relative abundance of Oscillospira significantly decreased in the inulin group at ZT4 (Figure 2b). We analyzed the PCoA of the weighted UniFrac distances and determined the beta-diversity of the microbiota composition (Figure S2a). In this experiment, we focused on the influence of inulin on the microbiota; thus, we primarily compared cellulose and inulin feeding. The beta-diversity of the microbiota composition was significantly different between the cellulose and inulin groups at ZT20 but not at ZT4 (Figure S2b,c).

These results suggest that inulin consumption changes microbiota composition. In addition, the inulin feeding time may have different effects on the microbiota because changes in the microbiota were more prominent at ZT20 (morning) than at ZT4 (evening), which showed significant and non-significant differences, respectively, compared with the cellulose group.

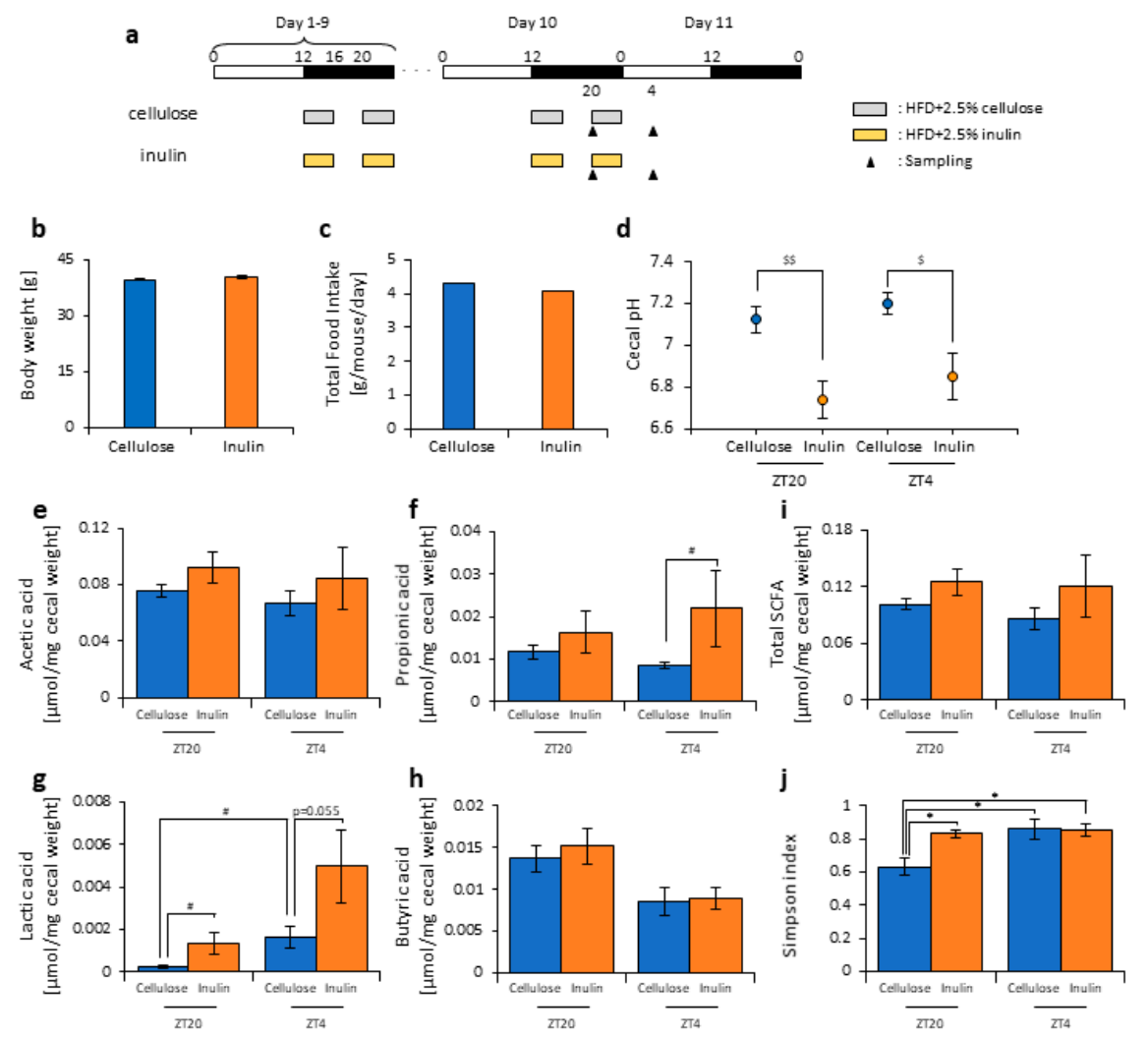

Figure 1. Inulin feeding decreased cecal $\mathrm{pH}$ and increased short-chain-fatty-acids. (a) Experimental schedule, where the white and black bars indicate environmental $12 \mathrm{~h}$ light and dark conditions, respectively. The gray bar indicates feeding with a high-fat-diet (HFD) and $2.5 \%$ cellulose. The yellow bar indicates feeding with HFD and $2.5 \%$ inulin. The black arrowhead indicates the sampling time. (b) Body 
weight before sampling. (c) Average daily food intake. (d) Cecal $\mathrm{pH}$ of mice housed for 10 days for each group. (e-i) The short-chain fatty acids (SCFAs) of mice, including (e) acetic acid, (f) propionic acid, (g) lactic acid, (h) butyric acid, and (i) total SCFAs. (j) Bacterial alpha diversity. Comparison of the Simpson index estimation of the $16 \mathrm{~S}$ rDNA gene libraries at $97 \%$ similarity from the sequencing analysis. All values except (c) are represented as mean \pm SEM (cellulose at ZT20 ( $n=5)$ and $4(n=5)$; inulin at ZT20 $(\mathrm{n}=5)$ and $4(\mathrm{n}=5))$. ${ }^{*} p<0.05$, evaluated using the two-way ANOVA with Tukey's post hoc test. $\$ \$ p<0.01, \$ p<0.05$, evaluated using the two-way ANOVA with Sidak's post hoc test. $\# p<0.05$, evaluated using the Mann-Whitney test with a two-stage linear step-up procedure of the Benjamini, Krieger, and Yekutieli test for multiple comparisons.
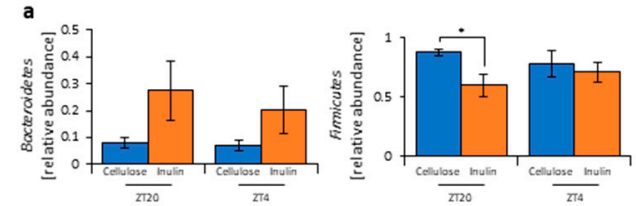

b
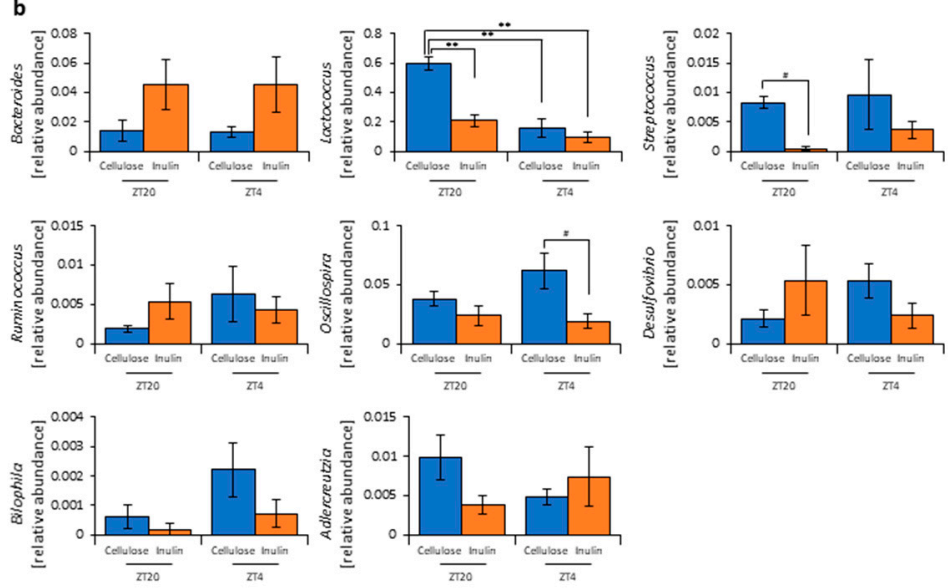

Figure 2. Inulin feeding changed the relative abundance of some bacteria. (a) Phylum level. (b) Genus level. All values are represented as mean \pm SEM (cellulose at ZT20 $(n=5)$ and $4(n=5)$; inulin at ZT20 $(\mathrm{n}=5)$ and $4(\mathrm{n}=5)) .{ }^{* *} p<0.01,{ }^{*} p<0.05$, evaluated using the two-way ANOVA with Tukey's post hoc test. \# $p<0.05$, evaluated using the Mann-Whitney test with a two-stage linear step-up procedure of the Benjamini, Krieger, and Yekutieli test for multiple comparisons.

3.2. Inulin Intake in the Morning Rather than the Evening Strongly Affected the Microbiota Composition under Time-Restricted Feeding Conditions

In this study, inulin may have had different effects on the microbiota depending on the feeding times. However, in experiment 1 , we did not measure the effect of the feeding pattern. It is possible that the effect of inulin was increased at ZT20 (four hours after the morning intake) due to the high consumption in the morning. In the next experiment, we examined whether morning or evening inulin feeding affected the microbiota under the two meals-per-day schedule. The mice were divided into three groups. Group 1 received cellulose and was fed an HFD with 5\% cellulose in the morning and evening. Group 2 received inulin in the morning and was fed an HFD with 5\% inulin in the morning and an HFD with 5\% cellulose in the evening. Group 3 received inulin in the evening and was fed an HFD with 5\% cellulose in the morning and an HFD with 5\% inulin in the evening. The mice were housed under each condition for 10 days, after which they were sacrificed at ZT20 and ZT4 on days 10-11 (Figure 3a). We sampled cecal contents and feces and measured the cecal $\mathrm{pH}$. There was no significant difference in body weight between any group before sacrifice (Figure 3b), nor was there a large difference in total food intake between them. However, the total food intake was slightly higher if inulin intake was in the morning rather than in the evening (Figure 3c). The cecal $\mathrm{pH}$ was significantly lower in the morning inulin group than in the morning cellulose or evening inulin groups 
at ZT20. On the contrary, the $\mathrm{pH}$ was significantly lower in the evening inulin group than in the evening cellulose and morning inulin groups at ZT4 (Figure 3d). The acetic acid, propionic acid, lactic acid, butyric acid, and total SCFA levels were significantly higher in the morning inulin group than in the morning cellulose or evening inulin groups at ZT20. However, the acetic acid, propionic acid, lactic acid, butyric acid, and total SCFA levels were significantly higher in the evening inulin group than in the evening cellulose or morning inulin groups at ZT4 (Figure 3e-i).

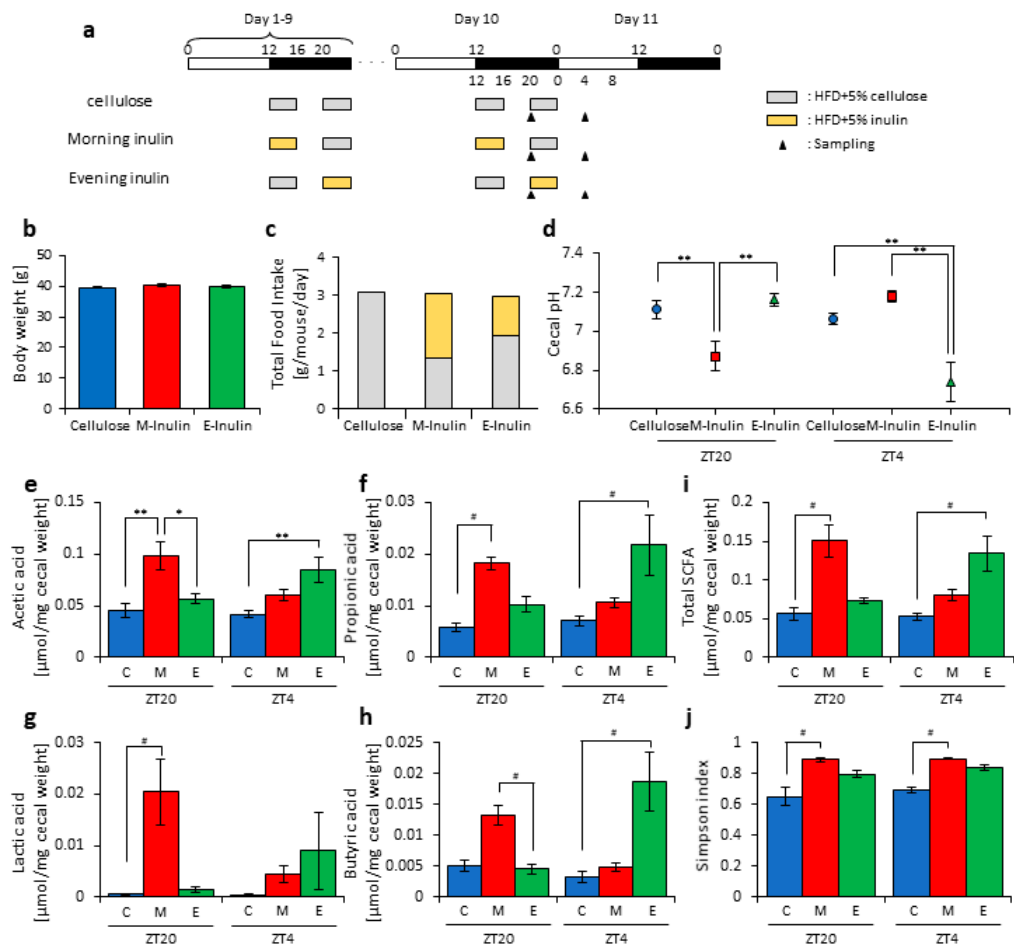

Figure 3. Morning inulin feeding decreased cecal $\mathrm{pH}$ and increased short-chain-fatty-acids more than evening inulin feeding. (a) Experimental schedule, where white and black bars indicate environmental $12 \mathrm{~h}$ light and dark conditions, respectively. The gray bar indicates feeding with a high-fat-diet (HFD) and $5 \%$ cellulose. The yellow bar indicates feeding with HFD and 5\% inulin. The black arrowhead indicates the sampling time. (b) Body weight before sampling. (c) Average daily food intake. The gray bar indicates the average daily food intake of cellulose, and the yellow bar indicates the average daily food intake of inulin. (d) Cecal $\mathrm{pH}$ of mice housed for 10 days for each group. (e-i) SCFAs of mice, including (e) acetic acid, (f) propionic acid, (g) lactic acid, (h) butyric acid, and (i) total SCFAs. (j) Bacterial alpha diversity. Comparison of the Simpson index estimation of the 16S rDNA gene libraries at $97 \%$ similarity from the sequencing analysis. All values except (c) are represented as mean \pm SEM (cellulose at ZT20 (n=5) and $4(n=5)$; morning inulin at ZT20 $(n=5)$ and $4(n=5)$; evening inulin at ZT20 $(\mathrm{n}=5)$ and $4(\mathrm{n}=5)) .{ }^{* *} p<0.01,{ }^{*} p<0.05$, evaluated using the two-way ANOVA with Tukey's post hoc test. \# $p<0.05$, evaluated using the Kruskal-Wallis test with Dunn post hoc test with a two-stage linear step-up procedure of the Benjamini, Krieger, and Yekutieli test for multiple comparisons. Cellulose, morning inulin, and evening inulin are C, M, or E, respectively.

Next, we extracted 16S rDNA from the mice feces and analyzed the microbiota. The value of alpha-diversity as determined by the Simpson index was significantly higher in the morning inulin group than in the morning cellulose or evening inulin groups at both ZT20 and ZT4 (Figure 3j). We also examined the differences between the changes of the relative abundance of taxa between the inulin and cellulose groups. Some of the detected bacteria are shown in Figure 4. At the phylum level, the relative abundance of Bacteroidetes was significantly higher in the morning inulin group than in the morning cellulose group at ZT20. Meanwhile, the relative abundance of Firmicutes was significantly lower in the morning inulin group than in the morning cellulose and evening inulin groups at ZT20 
as well as significantly lower in the evening inulin group than in the evening cellulose group at ZT4 (Figure 4a). At the genus level, the relative abundance of Lactococcus was significantly decreased in the morning inulin group at both ZT20 and ZT4 and in the evening inulin group at ZT4, while the relative abundance of Dorea and Allobaculum was significantly increased in the morning inulin group (Figure 4b). We analyzed the PCoA of the weighted UniFrac distances and determined the beta-diversity of the microbiota composition (Figure S3a). At ZT20, the beta-diversity of the microbiota was significantly different between the cellulose and morning inulin groups and the morning and evening inulin groups (Figure S3b). At ZT4, the beta-diversity of the microbiota composition was significantly different among all of the groups (Figure S3c).
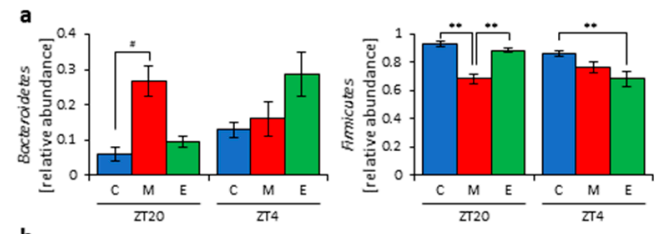

b
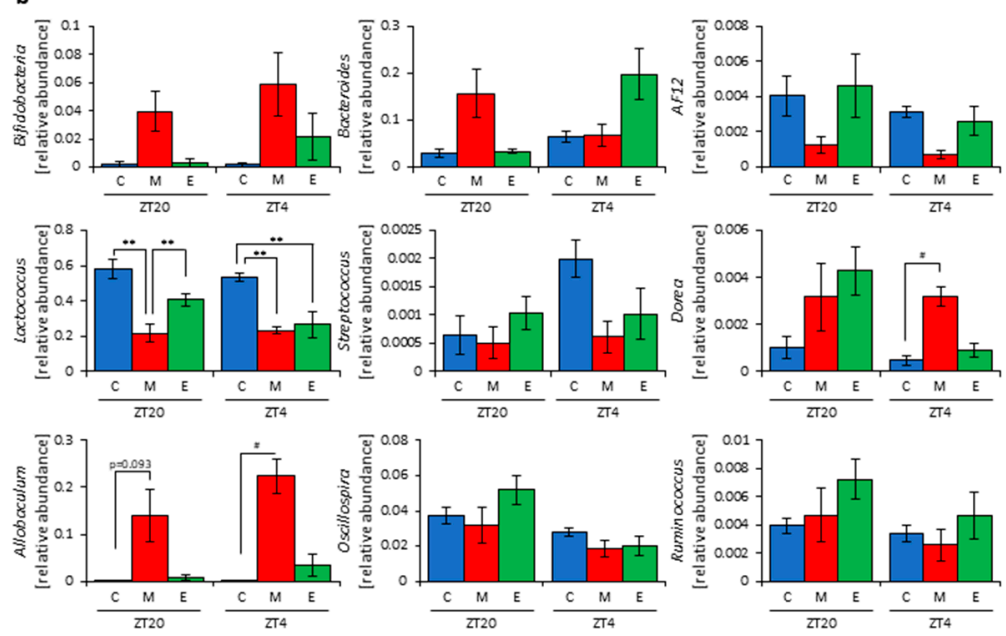

Figure 4. Morning inulin feeding changed the relative abundance of some bacteria. (a) Phylum level. (b) Genus level. All values are represented as mean \pm SEM (cellulose at ZT20 $(n=5)$ and $4(n=5)$; morning inulin at ZT20 (n=5) and $4(\mathrm{n}=5)$; evening inulin at ZT20 $(\mathrm{n}=5)$ and $4(\mathrm{n}=5)) .{ }^{* *} p<0.01$, evaluated using the two-way ANOVA with Tukey's post hoc test. \# $p<0.05$, evaluated using the Kruskal-Wallis test with Dunn post hoc test with a two-stage linear step-up procedure of the Benjamini, Krieger, and Yekutieli test for multiple comparisons. Cellulose, morning inulin, and evening inulin are $\mathrm{C}, \mathrm{M}$, or E, respectively.

These results suggest that morning inulin feeding affected the microbiota more than evening inulin feeding. However, the inulin intake was higher in the morning inulin group. Therefore, the increased consumption of the morning inulin group may have had more of an impact on the microbiota. To eliminate the effects of different food intakes, we prepared an apparatus to supply equal food amounts at two meals per day in the next experiment.

\subsection{Inulin Feeding in the Morning Affected the Microbiota Composition More than that in the Evening under Restricted Food Amount Conditions}

In this experiment, we provided the mice with two meals per day of $1.8 \mathrm{~g}$ of food at ZT12 (morning) and ZT20 (evening) to achieve equal food intake. The mice were divided into three groups. Group 1 received cellulose and was fed $1.8 \mathrm{~g}$ of an HFD with 5\% cellulose in both the morning and evening. Group 2 received inulin in the morning and was fed $1.8 \mathrm{~g}$ of an HFD with $5 \%$ inulin in the morning and $1.8 \mathrm{~g}$ of an HFD with 5\% cellulose in the evening. Group 3 received inulin in the evening and was fed $1.8 \mathrm{~g}$ of an HFD with 5\% cellulose in the morning and $1.8 \mathrm{~g}$ of an HFD with $5 \%$ inulin in the 
evening. The mice were housed under each condition for 14 days, after which they were sacrificed at ZT20 and ZT4 on days 14-15 (Figure 5a). We sampled cecal content and feces and measured the cecal $\mathrm{pH}$. There was no significant difference in body weight between any group before sacrifice (Figure $5 \mathrm{~b}$ ). The cecal $\mathrm{pH}$ was significantly lower in the morning inulin group than in the morning cellulose group and significantly lower in the evening inulin group than in the evening cellulose group. Moreover, the cecal $\mathrm{pH}$ was significantly lower in the morning inulin group than in the evening inulin group (Figure 5c). The propionic acid, lactic acid, butyric acid, and total SCFA levels were significantly higher in the morning inulin group than in the morning cellulose group, while the propionic acid level was significantly higher in the evening inulin group than in the evening cellulose group (Figure $5 d-h$ ).

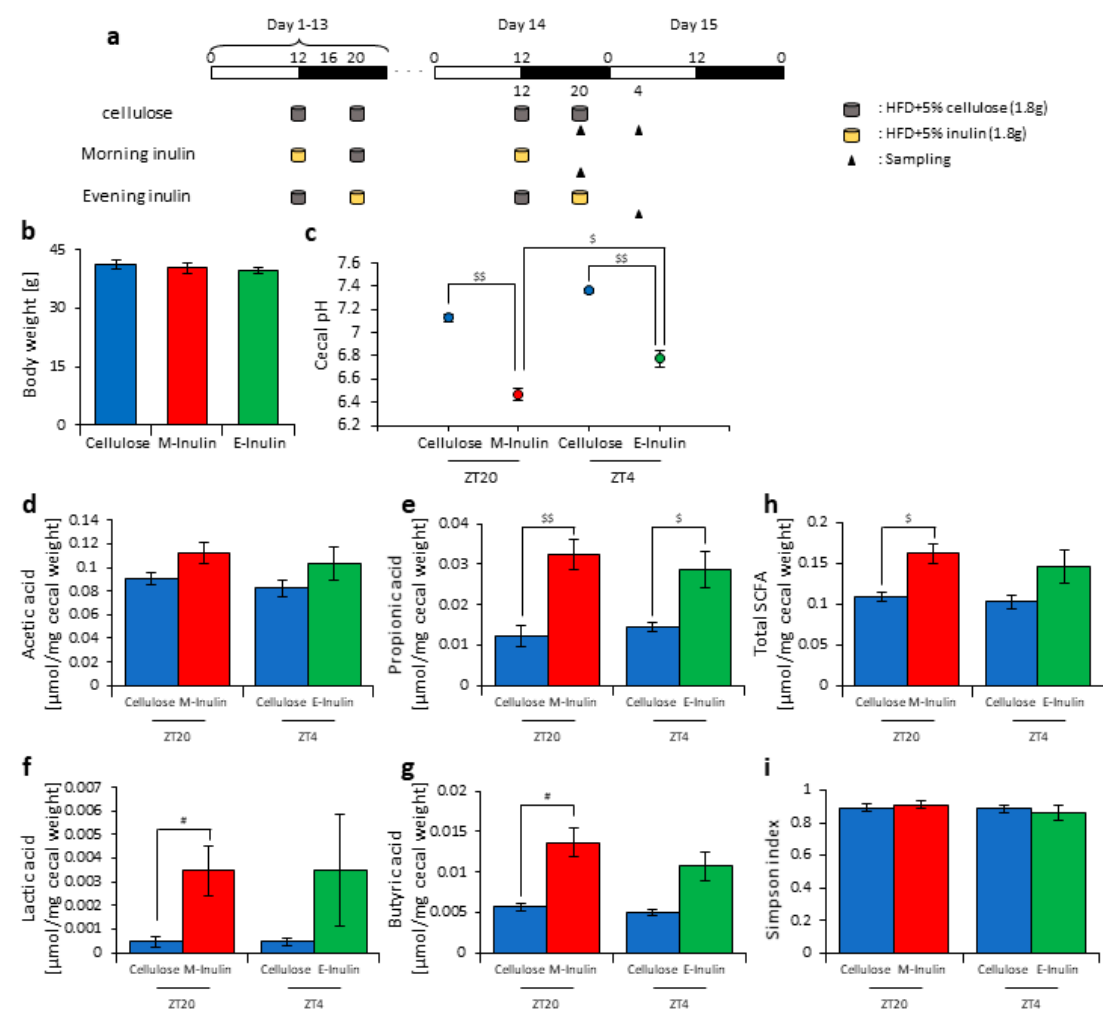

Figure 5. Morning inulin feeding decreased cecal $\mathrm{pH}$ and increased short-chain-fatty-acids more than evening inulin feeding under equivalent feeding conditions. (a) Experimental schedule, where white and black bars indicate environmental $12 \mathrm{~h}$ light and dark conditions, respectively. The gray cylinder indicates the $1.8 \mathrm{~g}$ of high-fat-diet (HFD) with 5\% cellulose. The yellow cylinder indicates the $1.8 \mathrm{~g}$ of HFD with $5 \%$ inulin. The black arrowhead indicates the sampling time. (b) Body weight before sampling. (c) Cecal pH of mice housed for 14 days for each group. (d-h) SCFAs of mice, including (d) acetic acid, (e) propionic acid, (f) lactic acid, (g) butyric acid, and (h) total SCFAs. (i) Bacterial alpha diversity. Comparison of the Simpson index estimation of the $16 \mathrm{~S}$ rDNA gene libraries at $97 \%$ similarity from the sequencing analysis. All values are represented as mean \pm SEM (cellulose at ZT20 ( $\mathrm{n}=4)$ and $4(\mathrm{n}=4)$; morning inulin $(\mathrm{n}=5)$; evening inulin $(\mathrm{n}=5)) . \$ \$ p<0.01, \$ p<0.05$, evaluated using the two-way ANOVA with Sidak's post hoc test. \# $p<0.05$, evaluated using the Mann-Whitney test with a two-stage linear step-up procedure of the Benjamini, Krieger, and Yekutieli test for multiple comparisons.

Next, we extracted 16S rDNA from the mice feces and analyzed the microbiota. The value of alpha-diversity as determined by the Simpson index showed no significant difference between any group (Figure 5i). We also examined the differences in the changes of the relative abundance of taxa. Bacteria detected in over half of all samples are shown in Table 1. At the phylum level, the relative abundance of Proteobacteria was significantly increased in the morning inulin group, while the relative abundance of TM7 was significantly decreased in the morning and evening inulin groups (Table 1a). 
At the genus level, the relative abundance of Butyricimonas was significantly increased in the morning inulin group, while the relative abundance of AF12, Staphylococcus, Lactococcus, Oscillospira, Bilophila, and Desulfovibrio was significantly decreased in the morning inulin group. Meanwhile, the relative abundance of AF12, Odoribacter, and Oscillospira was significantly decreased in the evening inulin group (Table $1 \mathrm{~b}$ ). The number of bacteria changed by inulin feeding in the morning was higher than that changed by inulin feeding in the evening. We analyzed the PCoA of the weighted UniFrac distances and determined the beta-diversity of the microbiota composition (Figure S4a). The beta-diversity of the microbiota was significantly different between the cellulose group and morning inulin group (Figure S4b), but no significant difference was observed between the cellulose group and evening inulin group (Figure S4c). We predicted the functional profiles from sequencing data with PICRUSt. Among the categories related to "carbohydrate metabolism", the relative abundance of fructose and mannose metabolism was significantly increased in the morning inulin group but not in the evening inulin group (Figure S4d).

These results suggest that inulin feeding in the morning may affect the microbiota, even if the food intake amount is the same in the morning and evening.

Table 1. The relative abundance of some bacteria under the condition of two meals per day. (a). Phylum level. (b). Genus level.

\begin{tabular}{|c|c|c|c|c|c|c|}
\hline \multicolumn{7}{|c|}{ a. Phylum Level } \\
\hline \multirow{2}{*}{ Bacterial } & \multicolumn{3}{|c|}{ ZT20 } & \multicolumn{3}{|c|}{ ZT4 } \\
\hline & Cellulose & M-Inulin & $p$-Value & Cellulose & E-Inulin & $p$-Value \\
\hline Actinobacteria & $0.0072 \pm 0.0039$ & $0.0103 \pm 0.0081$ & 0.7143 & $0.0690 \pm 0.0647$ & $0.0907 \pm 0.0440$ & 0.8254 \\
\hline Bacteroidetes & $0.1535 \pm 0.0463$ & $0.2499 \pm 0.0654$ & 0.669 & $0.1647 \pm 0.0467$ & $0.3644 \pm 0.1203$ & 0.2085 \\
\hline Deferribacteres & $0.0011 \pm 0.0010$ & $0.0005 \pm 0.0004$ & 0.9999 & $0.0002 \pm 0.0002$ & $0.0004 \pm 0.0003$ & 0.8413 \\
\hline Firmicutes & $0.8221 \pm 0.0467$ & $0.6863 \pm 0.0713$ & 0.3232 & $0.7486 \pm 0.0228$ & $0.5294 \pm 0.0865$ & 0.0743 \\
\hline Proteobacteria & $0.0111 \pm 0.0033$ & $0.0019 \pm 0.0004$ & $0.0159^{\#}$ & $0.0152 \pm 0.0030$ & $0.0054 \pm 0.0017$ & 0.1905 \\
\hline TM7 & $0.0043 \pm 0.0025$ & $0.0004 \pm 0.0003$ & $0.0159^{\#}$ & $0.0017 \pm 0.0002$ & $0.0001 \pm 0.0001$ & $0.0159^{\#}$ \\
\hline Verrucomicrobia & $0.0006 \pm 0.0003$ & $0.0473 \pm 0.0219$ & 0.1905 & $0.0003 \pm 0.003$ & $0.0132 \pm 0.0117$ & 0.1032 \\
\hline \multicolumn{7}{|c|}{ b. Genus Level } \\
\hline \multirow{2}{*}{ Bacterial } & \multicolumn{3}{|c|}{ ZT20 } & \multicolumn{3}{|c|}{ ZT4 } \\
\hline & Cellulose & M-Inulin & $p$-Value & Cellulose & E-Inulin & $p$-Value \\
\hline Bifidobacterium & $0.0022 \pm 0.0018$ & $0.0080 \pm 0.0077$ & 0.5556 & $0.0063 \pm 0.0062$ & $0.0088 \pm 0.0044$ & 0.6825 \\
\hline Adlercreutzia & $0.0046 \pm 0.0019$ & $0.0022 \pm 0.0004$ & 0.2344 & $0.0047 \pm 0.0014$ & $0.0026 \pm 0.0006$ & 0.6428 \\
\hline Bacteroides & $0.0463 \pm 0.0175$ & $0.1100 \pm 0.0262$ & 0.0993 & $0.0701 \pm 0.0238$ & $0.1953 \pm 0.0627$ & 0.1352 \\
\hline Parabacteroides & $0.0010 \pm 0.0003$ & $0.0009 \pm 0.0002$ & 0.8247 & $0.0015 \pm 0.0006$ & $0.0010 \pm 0.0003$ & 0.6229 \\
\hline AF12 & $0.0075 \pm 0.0023$ & $0.0011 \pm 0.0006$ & $0.0435^{\#}$ & $0.0052 \pm 0.0013$ & $0.0009 \pm 0.0002$ & $0.0317^{\#}$ \\
\hline Butyricimonas & $0.0004 \pm 0.0001$ & $0.0008 \pm 0.0004$ & $0.0317^{\#}$ & $0.0005 \pm 0.0003$ & $0.0002 \pm 0.0001$ & 0.7937 \\
\hline Odoribacter & $0.0017 \pm 0.0003$ & $0.0006 \pm 0.0002$ & 0.1795 & $0.0020 \pm 0.0008$ & $0.0003 \pm 0.0001$ & $0.0308^{\$}$ \\
\hline [Prevotella] & $0.0144 \pm 0.0085$ & $0.0303 \pm 0.0098$ & 0.2857 & $0.0118 \pm 0.0064$ & $0.0375 \pm 0.0279$ & 0.9762 \\
\hline Staphylococcus & $0.0013 \pm 0.0006$ & $0.0002 \pm 0.0001$ & $0.0397^{\#}$ & $0.0009 \pm 0.0006$ & $0.0005 \pm 0.0002$ & 0.8254 \\
\hline Lactobacillus & $0.0294 \pm 0.0230$ & $0.0136 \pm 0.0036$ & 0.6825 & $0.1152 \pm 0.0811$ & $0.0631 \pm 0.0323$ & 0.873 \\
\hline Lactococcus & $0.2862 \pm 0.0453$ & $0.0957 \pm 0.0128$ & $0.0159^{\#}$ & $0.1691 \pm 0.0446$ & $0.0856 \pm 0.0136$ & 0.2857 \\
\hline Streptococcus & $0.0034 \pm 0.0016$ & $0.0011 \pm 0.0002$ & 0.1545 & $0.0037 \pm 0.0016$ & $0.0019 \pm 0.0010$ & 0.357 \\
\hline Clostridium & $0.0002 \pm 0.0001$ & $0.0001 \pm 0.00005$ & 0.3889 & $0.0014 \pm 0.0012$ & $0.0003 \pm 0.0002$ & 0.3889 \\
\hline Dehalobacterium & $0.0018 \pm 0.0002$ & $0.0017 \pm 0.0006$ & 0.873 & $0.0010 \pm 0.0001$ & $0.0010 \pm 0.0007$ & 0.1746 \\
\hline Coprococcus & $0.0049 \pm 0.0009$ & $0.0081 \pm 0.0032$ & 0.9999 & $0.0035 \pm 0.0007$ & $0.0019 \pm 0.0005$ & 0.1905 \\
\hline Dorea & $0.0032 \pm 0.0011$ & $0.0032 \pm 0.0012$ & 0.9966 & $0.0041 \pm 0.0031$ & $0.0020 \pm 0.0012$ & 0.5089 \\
\hline Roseburia & $0.0018 \pm 0.0010$ & $0.0053 \pm 0.0038$ & 0.9762 & $0.0005 \pm 0.0004$ & $0.0004 \pm 0.0001$ & 0.5635 \\
\hline [Ruminococcus] & $0.0305 \pm 0.0113$ & $0.0384 \pm 0.0105$ & 0.6271 & $0.0327 \pm 0.0129$ & $0.0240 \pm 0.0094$ & 0.5957 \\
\hline Oscillospira & $0.0803 \pm 0.0131$ & $0.0290 \pm 0.0088$ & $0.0148^{\$}$ & $0.0600 \pm 0.0173$ & $0.0172 \pm 0.0074$ & $0.0404^{\$}$ \\
\hline Ruminococcus & $0.0096 \pm 0.0019$ & $0.0067 \pm 0.0032$ & 0.4961 & $0.0056 \pm 0.0017$ & $0.0025 \pm 0.0010$ & 0.161 \\
\hline Allobaculum & $0.0017 \pm 0.0007$ & $0.1764 \pm 0.0544$ & 0.1905 & $0.0662 \pm 0.0649$ & $0.1669 \pm 0.1094$ & 0.5238 \\
\hline Bilophila & $0.0013 \pm 0.0003$ & $0.0003 \pm 0.0002$ & $0.01599^{\#}$ & $0.0011 \pm 0.0005$ & $0.0002 \pm 0.0001$ & 0.1111 \\
\hline
\end{tabular}


Table 1. Cont.

\begin{tabular}{ccccccc}
\hline \multirow{2}{*}{ Bacterial } & \multicolumn{5}{c}{ b. Genus Level } \\
\cline { 2 - 7 } & Cellulose & M-Inulin & $p$-Value & Cellulose & E-Inulin & $p$-Value \\
\hline Desulfovibrio & $0.0037 \pm 0.0011$ & $0.0006 \pm 0.0004$ & $0.047^{\#}$ & $0.0021 \pm 0.0007$ & $0.0019 \pm 0.0002$ & 0.371 \\
Akkermansia & $0.0006 \pm 0.0002$ & $0.0473 \pm 0.0219$ & 0.1905 & $0.0003 \pm 0.0003$ & $0.0132 \pm 0.0117$ & 0.1032 \\
\hline
\end{tabular}

(a) Number of bacteria significantly changed by M-inulin/all number of bacteria well-detected = 2/7. Number of bacteria significantly changed by E-inulin/all number of bacteria well-detected $=1 / 7 .{ }^{\#} p<0.05$, evaluated using the Mann-Whitney test with a two-stage linear step-up procedure of the Benjamini, Krieger, and Yekutieli test for multiple comparisons. (b) Number of bacteria significantly changed by M-inulin/all number of bacteria well-detected = 7/24. Number of bacteria significantly changed by E-inulin/all number of bacteria well-detected $=3 / 24 .{ }^{\$} p<0.05$, evaluated using the two-way ANOVA with Sidak post hoc test. ${ }^{\#} p<0.05$, evaluated using the Mann-Whitney test with a two-stage linear step-up procedure of the Benjamini, Krieger, and Yekutieli test for multiple comparisons.

\subsection{A Relationship Was Observed between the Length of Fasting Time and Inulin Feeding Stimulation}

In experiment 3 , it was observed that inulin intake in the morning may have an effect on the microbiota and that the fasting time factored into this effect in the morning. The morning inulin group fasted for $16 \mathrm{~h}$ after the previous feeding, while the evening inulin group fasted for $8 \mathrm{~h}$ after the previous feeding, meaning that the time until breakfast was longer than the time until dinner. Therefore, the difference in the length of fasting time may have changed the effect on the microbiota. To test this hypothesis, we prepared an experiment with equal fasting times based on one meal a day, in which $3.6 \mathrm{~g}$ of food was given to the mice at either ZT12 (morning) or ZT20 (evening). The mice were divided into four groups. Group 1 received cellulose in the morning and was fed $3.6 \mathrm{~g}$ of an HFD with $5 \%$ cellulose in the morning. Group 2 received inulin in the morning and was fed $3.6 \mathrm{~g}$ of an HFD with $5 \%$ inulin in the morning. Group 3 received cellulose in the evening and was fed $3.6 \mathrm{~g}$ of an HFD with 5\% cellulose in the evening. Group 4 received inulin in the evening and was fed $3.6 \mathrm{~g}$ of an HFD with 5\% inulin in the evening. The mice were housed under each condition for 14 days, after which they were sacrificed at ZT20 and ZT4 on days 14-15 (Figure 6a). We sampled cecal content and feces and measured the cecal $\mathrm{pH}$. The body weight was significantly increased in the evening cellulose and inulin groups compared with the morning cellulose and inulin groups. (Figure 6b). The cecal pH was significantly lower in the morning and evening inulin groups than in the morning and evening cellulose groups (Figure $6 \mathrm{c}$ ). The propionic and lactic acid levels were significantly higher in the morning inulin group than in the morning cellulose group. In addition, the butyric acid level was higher, albeit not significantly, in the morning inulin group than in the morning cellulose group. Meanwhile, the lactic and butyric acid levels were significantly higher in the evening inulin group than in the evening cellulose group, and the propionic acid level was higher, albeit not significantly, in the evening inulin group than in the evening cellulose group (Figure $6 \mathrm{~d}-\mathrm{h}$ ).

Next, we extracted 16S rDNA from the mice feces and analyzed the microbiota. The value of alpha-diversity as determined by the Simpson index was significantly higher in the morning cellulose group than in the evening cellulose group (Figure 6i). We also examined the differences in the changes of the relative abundance of taxa. Bacteria detected in over half of all samples are shown in Table 2. At the phylum level, the relative abundance of Actinobacteria was increased in the morning inulin group, but there was no significant difference in the relative abundance in the evening inulin group (Table 2a). At the genus level, the relative abundance of Bifidobacterium and Allobaculum was significantly increased in the morning inulin group, while the relative abundance of Streptococcus, Oscillospira, and Ruminococcus was significantly decreased in the morning inulin group. Meanwhile, the relative abundance of Dorea and Allobaculum was significantly increased in the evening inulin group, and the relative abundance of Staphylococcus and Lactococcus was significantly decreased in the evening inulin group (Table $2 b$ ). The number of bacteria changed by inulin feeding in either the morning or the evening was similar. We analyzed the PCoA of the weighted UniFrac distances and determined the beta-diversity of the microbiota composition (Figure S5a). The beta-diversity of the 
microbiota was not significantly different between the cellulose and inulin groups in either the morning or evening (Figure S5b,c). We predicted the functional profiles from sequencing data with PICRUSt. Among the categories related to "carbohydrate metabolism", the relative abundance of fructose and mannose metabolism was not significantly different between the cellulose and inulin groups in either the morning or evening (Figure S5d). These results suggest that inulin intake in either the morning or evening with equal fasting periods does not change microbiota beta-diversity.

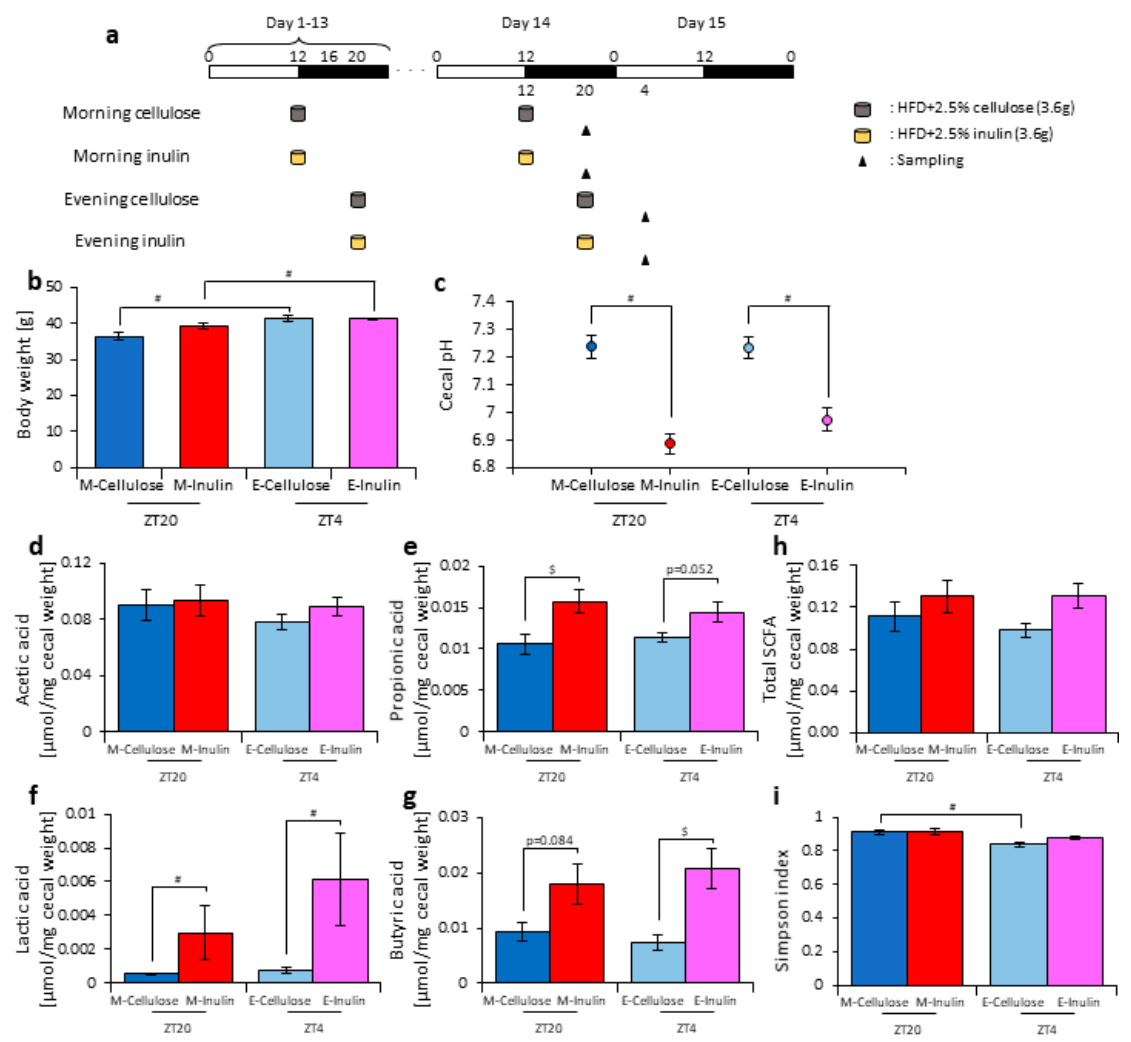

Figure 6. When fasting times are equal, the difference between morning and evening inulin feeding disappears. (a) Experimental schedule, where white and black bars indicate environmental $12 \mathrm{~h}$ light and dark conditions, respectively. The gray cylinder indicates the $3.6 \mathrm{~g}$ high-fat-diet (HFD) with $2.5 \%$ cellulose. The yellow cylinder indicates the $3.6 \mathrm{~g}$ of HFD with $2.5 \%$ inulin. The black arrowhead indicates the sampling time. (b) Body weight before sampling. (c) Cecal pH of mice housed for 14 days for each group. (d-h) SCFAs of mice, including (d) acetic acid, (e) propionic acid, (f) lactic acid, (g) butyric acid, and (h) total SCFAs. (i) Bacterial alpha diversity. Comparison of the Simpson index estimation of the $16 \mathrm{~S}$ rDNA gene libraries at $97 \%$ similarity from the sequencing analysis. All values are represented as mean \pm SEM (morning cellulose $(n=6)$; morning inulin $(n=6)$; evening cellulose $(n=6)$; evening inulin $(n=6)) . \$ p<0.05$, evaluated using the two-way ANOVA with Sidak's post hoc test. \# $p<0.05$, evaluated using the Mann-Whitney test with a two-stage linear step-up procedure of the Benjamini, Krieger, and Yekutieli test for multiple comparisons. The table in ( $\mathbf{j}$ ) indicates the results using permutational multivariate analysis of variance (PERMANOVA). Morning cellulose, morning inulin, evening cellulose, or evening inulin are represented as M-cellulose, M-inulin, E-cellulose or E-inulin, respectively. 
Table 2. The relative abundance of some bacteria under the condition of one meal per day. (a). Phylum level. (b). Genus level.

\begin{tabular}{|c|c|c|c|c|c|c|}
\hline \multicolumn{7}{|c|}{ a. Phylum Level } \\
\hline \multirow{2}{*}{ Bacterial } & \multicolumn{3}{|c|}{ ZT20 } & \multicolumn{3}{|c|}{ ZT4 } \\
\hline & Cellulose & M-Inulin & $p$-Value & Cellulose & E-Inulin & $p$-Value \\
\hline Actinobacteria & $0.0041 \pm 0.0017$ & $0.0364 \pm 0.0199$ & $0.0174^{\#}$ & $0.0321 \pm 0.0154$ & $0.0871 \pm 0.0380$ & 0.1797 \\
\hline Bacteroidetes & $0.0759 \pm 0.0296$ & $0.1372 \pm 0.0337$ & 0.3748 & $0.1024 \pm 0.0275$ & $0.1609 \pm 0.0411$ & 0.4069 \\
\hline Deferribacteres & $0.0037 \pm 0.0016$ & $0.0018 \pm 0.0006$ & 0.5714 & $0.0007 \pm 0.0004$ & $0.0002 \pm 0.00006$ & 0.4459 \\
\hline Firmicutes & $0.80427 \pm 0.0240$ & $0.7513 \pm 0.0306$ & 0.1797 & $0.7832 \pm 0.0207$ & $0.6906 \pm 0.0373$ & 0.1298 \\
\hline Proteobacteria & $0.1119 \pm 0.0161$ & $0.0706 \pm 0.0120$ & 0.0799 & $0.0790 \pm 0.0141$ & $0.0568 \pm 0.0102$ & 0.4449 \\
\hline Verrucomicrobia & $0.0001 \pm 0.0001$ & $0.0025 \pm 0.0011$ & 0.0606 & $0.0025 \pm 0.0022$ & $0.0042 \pm 0.0036$ & 0.5455 \\
\hline \multicolumn{7}{|c|}{ b. Genus Level } \\
\hline \multirow{2}{*}{ Bacterial } & \multicolumn{3}{|c|}{ ZT20 } & \multicolumn{3}{|c|}{ ZT4 } \\
\hline & Cellulose & M-Inulin & $p$-Value & Cellulose & E-Inulin & $p$-Value \\
\hline Bifidobacterium & $0.0004 \pm 0.0003$ & $0.0305 \pm 0.0192$ & $0.0043^{\# \#}$ & $0.0266 \pm 0.0151$ & $0.0785 \pm 0.0367$ & 0.1775 \\
\hline Adlercreutzia & $0.0036 \pm 0.0017$ & $0.0037 \pm 0.0010$ & 0.5714 & $0.0051 \pm 0.0008$ & $0.0041 \pm 0.0008$ & 0.3874 \\
\hline Bacteroides & $0.0222 \pm 0.0103$ & $0.0327 \pm 0.0078$ & 0.4395 & $0.0149 \pm 0.0051$ & $0.0313 \pm 0.0101$ & 0.1801 \\
\hline Parabacteroides & $0.0059 \pm 0.0027$ & $0.0032 \pm 0.0010$ & 0.8983 & $0.0048 \pm 0.0012$ & $0.0025 \pm 0.0005$ & 0.3874 \\
\hline Butyricimonas & $0.0002 \pm 0.00008$ & $0.0001 \pm 0.00004$ & 0.6623 & $0.0003 \pm 0.0001$ & $0.0002 \pm 0.0001$ & 0.6591 \\
\hline Odoribacter & $0.0015 \pm 0.0003$ & $0.0022 \pm 0.0012$ & 0.8983 & $0.0023 \pm 0.0004$ & $0.0031 \pm 0.0007$ & 0.3874 \\
\hline [Prevotella] & $0.0066 \pm 0.0031$ & $0.0151 \pm 0.0102$ & 0.5541 & $0.0033 \pm 0.0018$ & $0.0056 \pm 0.0045$ & 0.9805 \\
\hline Mucispirillum & $0.0037 \pm 0.0016$ & $0.0018 \pm 0.0006$ & 0.5714 & $0.0007 \pm 0.0004$ & $0.0001 \pm 0.00006$ & 0.4459 \\
\hline Staphylococcus & $0.0005 \pm 0.0002$ & $0.00005 \pm 0.00003$ & 0.145 & $0.0009 \pm 0.0004$ & $0.00007 \pm 0.00002$ & 0.0022 \#\# \\
\hline Lactobacillus & $0.0080 \pm 0.0031$ & $0.0088 \pm 0.0027$ & 0.8983 & $0.1050 \pm 0.0530$ & $0.01225 \pm 0.0046$ & 0.1797 \\
\hline Lactococcus & $0.2490 \pm 0.0332$ & $0.1468 \pm 0.0205$ & 0.094 & $0.3408 \pm 0.0271$ & $0.1824 \pm 0.0494$ & $0.0078^{\$ \$}$ \\
\hline Streptococcus & $0.0048 \pm 0.0011$ & $0.0013 \pm 0.0002$ & $0.0087^{\# \#}$ & $0.0037 \pm 0.0005$ & $0.0023 \pm 0.0006$ & 0.0931 \\
\hline SMB53 & $0.0102 \pm 0.0079$ & $0.0130 \pm 0.0078$ & 0.9394 & $0.0467 \pm 0.0224$ & $0.0132 \pm 0.0076$ & 0.1688 \\
\hline Dehalobacterium & $0.0017 \pm 0.0004$ & $0.0024 \pm 0.0006$ & 0.5628 & $0.0007 \pm 0.0002$ & $0.0021 \pm 0.0008$ & 0.132 \\
\hline Blautia & $0.0004 \pm 0.0001$ & $0.0003 \pm 0.00008$ & 0.7381 & $0.0002 \pm 0.0001$ & $0.0003 \pm 0.0001$ & 0.1991 \\
\hline Coprococcus & $0.0093 \pm 0.0009$ & $0.0116 \pm 0.0026$ & 0.7879 & $0.0028 \pm 0.0005$ & $0.0048 \pm 0.0016$ & 0.3874 \\
\hline Dorea & $0.0017 \pm 0.0004$ & $0.0034 \pm 0.0007$ & 0.077 & $0.0011 \pm 0.0003$ & $0.0042 \pm 0.0006$ & $0.0016^{\$ \$}$ \\
\hline Roseburia & $0.00006 \pm 0.00002$ & $0.00005 \pm 0.00003$ & 0.9242 & $0.00007 \pm 0.00002$ & $0.0001 \pm 0.00007$ & 0.3398 \\
\hline [Ruminococcus] & $0.0652 \pm 0.0085$ & $0.0509 \pm 0.0082$ & 0.3544 & $0.0299 \pm 0.0059$ & $0.0347 \pm 0.0073$ & 0.882 \\
\hline Anaerotruncus & $0.0004 \pm 0.0001$ & $0.0001 \pm 0.00005$ & 0.1797 & $0.0001 \pm 0.00004$ & $0.0003 \pm 0.0001$ & 0.8312 \\
\hline Oscillospira & $0.0473 \pm 0.0076$ & $0.0213 \pm 0.0052$ & $0.0043 \$ \$$ & $0.0217 \pm 0.0042$ & $0.0158 \pm 0.0022$ & 0.6797 \\
\hline Ruminococcus & $0.0082 \pm 0.0009$ & $0.0034 \pm 0.0007$ & $0.0012 \$ \$$ & $0.0035 \pm 0.0008$ & $0.0020 \pm 0.0003$ & 0.7285 \\
\hline Allobaculum & $0.0011 \pm 0.0006$ & $0.1122 \pm 0.0562$ & $0.0022 \# \#$ & $0.0327 \pm 0.0157$ & $0.1703 \pm 0.0513$ & 0.0449 \# \\
\hline Catenibacterium & $0.0005 \pm 0.0001$ & $0.0003 \pm 0.0001$ & 0.3874 & $0.0004 \pm 0.00009$ & $0.0003 \pm 0.0001$ & 0.474 \\
\hline Desulfovibrio & $0.0010 \pm 0.0005$ & $0.0011 \pm 0.0007$ & 0.9073 & $0.0006 \pm 0.0002$ & $0.0023 \pm 0.0009$ & 0.1001 \\
\hline Citrobacter & $0.0030 \pm 0.0011$ & $0.0026 \pm 0.0004$ & 0.7879 & $0.0026 \pm 0.0004$ & $0.0015 \pm 0.0003$ & 0.0931 \\
\hline Klebsiella & $0.0417 \pm 0.0147$ & $0.0328 \pm 0.0138$ & 0.5714 & $0.0412 \pm 0.0105$ & $0.0291 \pm 0.0124$ & 0.1797 \\
\hline Akkermansia & $0.0001 \pm 0.0001$ & $0.0025 \pm 0.0011$ & 0.4545 & $0.0024 \pm 0.0022$ & $0.0041 \pm 0.0036$ & 0.5455 \\
\hline
\end{tabular}

(a) Number of bacteria significantly changed by M-inulin/all number of bacteria well-detected $=1 / 6$. Number of bacteria significantly changed by E-inulin/all number of bacteria well-detected $=0 / 6 .{ }^{\#} p<0.05$, evaluated using the Mann-Whitney test with a two-stage linear step-up procedure of the Benjamini, Krieger, and Yekutieli test for multiple comparisons. (b) Number of bacteria significantly changed by M-inulin/all number of bacteria well-detected $=5 / 28$. Number of bacteria significantly changed by E-inulin/all number of bacteria well-detected $=4 / 28$. $\$ \$<0.01$, evaluated using the two-way ANOVA with Sidak post hoc test. ${ }^{\# \#} p<0.01,{ }^{\#} p<0.05$, evaluated using the Mann-Whitney test with a two-stage linear step-up procedure of the Benjamini, Krieger, and Yekutieli test for multiple comparisons.

\section{Discussion}

In this study, inulin intake changed the composition and profile of the gut microbiota, increased SCFAs, and decreased the cecal pH (Figure 1, Figure 2 and Figure S2). SCFAs are important for health because they improve energy metabolism in the liver and muscles and immune function in the large 
intestine [9-11]. In addition, the effect of inulin on the microbiota was dependent on the timing of inulin intake. Therefore, we gave inulin to the mice in either the morning or evening. The microbiota was more affected by inulin feeding in the morning than in the evening (Figure 5 and Figure S4) because the fasting period was longer for the latter. There has been previous research on fasting time and dietary effects. Previous studies examining postprandial glucose metabolism have shown that breakfast, rather than dinner, can suppress postprandial hyperglycemia and that one of the primary factors is the difference in fasting time [51]. Additionally, in a previous study examining the circadian clock, a meal after a long fasting period strongly synchronized the peripheral clock [52,53]. Under a two-meals-per-day schedule in mice, the same amount of chow after $16 \mathrm{~h}$ of fasting could reset the Per2 gene expression rhythm in the liver clock compared with the same amount of chow after $6 \mathrm{~h}$ of fasting; in the two-meal experiments presented here, we used exactly the same protocol. In the current experiment, there was no difference in the cecal $\mathrm{pH}$ or SCFAs measurements between morning and evening with the same fasting duration (Figure $6 c, h$ ). Considering actual human life, the fasting time until breakfast is generally the longest among the three meals. Thus, these results, along with those of the previous study [53], support that inulin intake in the morning is most effective at attenuating HFD-induced changes of the gut microbiota. However, since the gut microbiota is also related to the circadian clock, there may be a difference between morning and evening in the gut microbiota composition, regardless of the fasting time. In addition to the daily feeding model used in this study, a feeding model for equalizing fasting time has been considered [52,54,55]. By using these feeding models, the relationship between fasting time and the effects of foods may be clarified. Moreover, the feeding model of this study has too long a starvation period compared with actual human life. Therefore, a feeding model that mimics the actual human lifestyle of three meals a day, as reported by Kuroda et al., may be considered for future experiments [52].

In this study, we first regulated the access time to inulin-containing food under a two-meals-per-day schedule because mice access food in the morning rather than in the evening under ad-lib food conditions $[54,56]$. Under these feeding conditions, we found clear effects of inulin in the morning. Therefore, in ad-lib feeding conditions, functional food intake at an earlier time during the active period may be a considerable factor in microbiota changes. Next, we regulated the food volume under a two-meals-per-day schedule. Once again, inulin in the morning had a clear effect on the microbiota, clarifying the importance of inulin intake in the morning on the beta-diversity and profile of the microbiota. However, in these experimental conditions, we did not control feeding and/or digestive speed; therefore, volume- and speed-controlled feeding systems may be required to determine the effect of feeding time.

The first meal after a long fast, most often breakfast, resets the phase of peripheral clock $[52,53]$. We recently demonstrated that cellobiose, a water-soluble dietary fiber, produces SCFAs, allowing them to reset the peripheral clock [21]. Taken together, these results suggest that the intake of inulin-containing foods in the morning may help reset the peripheral clock through SCFAs production.

Previous studies have reported that inulin consumption increases Bifidobacteria and Akkermancia muciniphila and decreases gram-positive cocci in humans and mice [47-50]. In this study, the gram-positive cocci Streptococcus and Staphylococcus decreased, but the A. muciniphila was not significantly changed. We considered that the degree of polymerization of inulin is one of the reasons that the results of this study differ from previous studies. In the structure of inulin, fructose is a monomer linked by 2-60 molecules with $\beta$-glycosidic bonds. The inulin used in this study had 16 fructose bonds (a degree of polymerization of 16) [34]. It has been reported that the influence on the microbiota is different depending on the degree of polymerization of inulin [48]. Therefore, the results may have been different with other degrees of polymerization.

Streptococcus is known to produce lactic acid [57,58], and Streptococcus mutans increases in the intestines of type 2 diabetes patients and is induced by a high-calorie diet [59]. Furthermore, Staphylococcus aureus is increased in obese patients, and Staphylococcus has a positive correlation with energy intake $[60,61]$. The SCFAs produced by inulin feeding increase the concentration of GLP-1 in 
the blood and promote insulin secretion [62]. Furthermore, SCFAs regulate insulin activity in adipose tissue through the GPR43 receptor [11]. Therefore, it has been suggested that inulin may be an effective food against diabetes. In fact, in rats and humans, inulin consumption inhibits blood glucose levels and lowers blood triglyceride levels and total cholesterol levels $[35,63,64]$. In this study, the species level was not fully detected, and blood glucose levels and triglycerides were not measured. If these factors were measured, we may have been able to clarify the relationship between the gut microbiota and glucose metabolism.

It has been reported that SCFAs produced by ingestion of water-soluble dietary fiber prevent fat accumulation in adipose tissue via GPR43 [11]. However, it has also been reported that water-soluble dietary fiber does not involve SCFAs and suppresses fatty acid accumulation itself. For example, water-soluble dietary fiber may form a highly viscous matrix in the small intestine, increase the viscosity of the small intestine, and then physically suppress fat absorption $[65,66]$. These reports should be considered when investigating the association between gut microbiota and lipid metabolism.

The analysis of the carbohydrate metabolism identified a significant association with the fructose and mannose metabolism in the morning inulin group under two meals per day but not under one meal per day. Inulin is a fructan polymerized with fructose. Therefore, it may be possible that fructose metabolism is more activated by inulin in the morning than in the evening. Furthermore, the production of SCFAs may be increased because fructose is metabolized in the morning. In addition, fructose metabolism may also be related to fasting time. PICRUSt is only a predictive tool. To determine accurate functional information of the related bacteria, metagenomic studies should be conducted. Additionally, the number of mice in each group should be increased to provide more accurate explanations regarding the microbiota and PICRUSt analysis.

\section{Conclusions}

In summary, inulin intake in the morning rather than in the evening affected the gut microbiota, promoted SCFAs production, and lowered the cecal $\mathrm{pH}$. The difference between the morning and evening results was related to the fasting duration, suggesting that there may be a relationship between fasting duration and meal stimulation regarding control of the microbiota.

Supplementary Materials: The following are available online at http://www.mdpi.com/2072-6643/11/11/2802/s1, Figure S1: the addition of cellulose does not affect the microbiota. Figure S2: inulin feeding in the morning changed the microbiota composition more than in the evening. Figure S3: morning inulin feeding changed the microbiota composition more than evening inulin feeding. Figure S4: morning inulin feeding changed the microbiota composition and the relative abundance of inferred functional profile more than evening inulin feeding under equivalent feeding conditions. Figure S5: the microbiota composition and the relative abundance of inferred functional profile was not significantly changed by inulin feeding, even under the condition of one meal per day.

Author Contributions: H.S., H.M. and S.S.; designed the research and analyzed the data. H.S. and S.S.; wrote the manuscript. H.S., H.M., A.W., Y.N., Y.L. and K.H.; performed the experiments.

Funding: This work was partially supported by the Council for Science, Technology, and Innovation, SIP, "Technologies for creating next-generation agriculture, forestry, and fisheries" (funding agency: Bio-oriented Technology Research Advancement Institution, NARO) (Shibata. S.) and Japan Society for the Promotion of Science (JSPS) KAKENHI (A and Houga) (Shibata. S).

Conflicts of Interest: We declare that there are no conflicts of interest related to this study.

\section{References}

1. Hooks, K.B.; O'Malley, M.A. Dysbiosis and its discontents. mBio 2017, 8, e01492-e01517. [CrossRef]

2. Ley, R.E.; Turnbaugh, P.J.; Klein, S.; Gordon, J.I. Microbial ecology: Human gut microbes associated with obesity. Nature 2006, 444, 1022-1023. [CrossRef] [PubMed]

3. Turnbaugh, P.J.; Ley, R.E.; Mahowald, M.A.; Magrini, V.; Mardis, E.R.; Gordon, J.I. An obesity-associated gut microbiome with increased capacity for energy harvest. Nature 2006, 444, 1027-1031. [CrossRef] [PubMed] 
4. Jahani-Sherafat, S.; Alebouyeh, M.; Moghim, S.; Ahmadi Amoli, H.; Ghasemian-Safaei, H. Role of gut microbiota in the pathogenesis of colorectal cancer; a review article. Gastroenterol. Hepatol. Bed Bench 2018, 11, 101-109.

5. Mai, V.; Morris, J.G., Jr. Need for prospective cohort studies to establish human gut microbiome contributions to disease risk. J. Natl. Cancer Inst. 2013, 105, 1850-1851. [CrossRef] [PubMed]

6. Jiang, H.; Ling, Z.; Zhang, Y.; Mao, H.; Ma, Z.; Yin, Y.; Wang, W.; Tang, W.; Tan, Z.; Shi, J.; et al. Altered fecal microbiota composition in patients with major depressive disorder. Brain Behav. Immun. 2015, 48, 186-194. [CrossRef] [PubMed]

7. Koh, A.; De Vadder, F.; Kovatcheva-Datchary, P.; Backhed, F. From dietary fiber to host physiology: Short-chain fatty acids as key bacterial metabolites. Cell 2016, 165, 1332-1345. [CrossRef] [PubMed]

8. den Besten, G.; van Eunen, K.; Groen, A.K.; Venema, K.; Reijngoud, D.J.; Bakker, B.M. The role of short-chain fatty acids in the interplay between diet, gut microbiota, and host energy metabolism. J. Lipid Res. 2013, 54, 2325-2340. [CrossRef]

9. Cummings, J.H.; Pomare, E.W.; Branch, W.J.; Naylor, C.P.; Macfarlane, G.T. Short chain fatty acids in human large intestine, portal, hepatic and venous blood. Gut 1987, 28, 1221-1227. [CrossRef]

10. Okada, T.; Fukuda, S.; Hase, K.; Nishiumi, S.; Izumi, Y.; Yoshida, M.; Hagiwara, T.; Kawashima, R.; Yamazaki, M.; Oshio, T.; et al. Microbiota-derived lactate accelerates colon epithelial cell turnover in starvation-refed mice. Nat. Commun. 2013, 4, 1654. [CrossRef]

11. Kimura, I.; Ozawa, K.; Inoue, D.; Imamura, T.; Kimura, K.; Maeda, T.; Terasawa, K.; Kashihara, D.; Hirano, K.; Tani, T.; et al. The gut microbiota suppresses insulin-mediated fat accumulation via the short-chain fatty acid receptor gpr43. Nat. Commun. 2013, 4, 1829. [CrossRef] [PubMed]

12. Bass, J.; Takahashi, J.S. Circadian integration of metabolism and energetics. Science 2010, 330, 1349-1354. [CrossRef] [PubMed]

13. Shibata, S.; Tahara, Y.; Hirao, A. The adjustment and manipulation of biological rhythms by light, nutrition, and abused drugs. Adv. Drug Deliv. Rev. 2010, 62, 918-927. [CrossRef] [PubMed]

14. Tahara, Y.; Aoyama, S.; Shibata, S. The mammalian circadian clock and its entrainment by stress and exercise. J. Physiol. Sci. JPS 2017, 67, 1-10. [CrossRef] [PubMed]

15. Tahara, Y.; Shibata, S. Entrainment of the mouse circadian clock: Effects of stress, exercise, and nutrition. Free Radic. Biol. Med. 2018, 119, 129-138. [CrossRef] [PubMed]

16. Sasaki, H.; Hattori, Y.; Ikeda, Y.; Kamagata, M.; Iwami, S.; Yasuda, S.; Tahara, Y.; Shibata, S. Forced rather than voluntary exercise entrains peripheral clocks via a corticosterone/noradrenaline increase in per2::Luc mice. Sci. Rep. 2016, 6, 27607. [CrossRef]

17. Leone, V.; Gibbons, S.M.; Martinez, K.; Hutchison, A.L.; Huang, E.Y.; Cham, C.M.; Pierre, J.F.; Heneghan, A.F.; Nadimpalli, A.; Hubert, N.; et al. Effects of diurnal variation of gut microbes and high-fat feeding on host circadian clock function and metabolism. Cell Host Microbe 2015, 17, 681-689. [CrossRef]

18. Liang, X.; Bushman, F.D.; FitzGerald, G.A. Rhythmicity of the intestinal microbiota is regulated by gender and the host circadian clock. Proc. Natl. Acad. Sci. USA 2015, 112, 10479-10484. [CrossRef]

19. Thaiss, C.A.; Zeevi, D.; Levy, M.; Zilberman-Schapira, G.; Suez, J.; Tengeler, A.C.; Abramson, L.; Katz, M.N.; Korem, T.; Zmora, N.; et al. Transkingdom control of microbiota diurnal oscillations promotes metabolic homeostasis. Cell 2014, 159, 514-529. [CrossRef]

20. Zarrinpar, A.; Chaix, A.; Yooseph, S.; Panda, S. Diet and feeding pattern affect the diurnal dynamics of the gut microbiome. Cell Metab. 2014, 20, 1006-1017. [CrossRef]

21. Tahara, Y.; Yamazaki, M.; Sukigara, H.; Motohashi, H.; Sasaki, H.; Miyakawa, H.; Haraguchi, A.; Ikeda, Y.; Fukuda, S.; Shibata, S. Gut microbiota-derived short chain fatty acids induce circadian clock entrainment in mouse peripheral tissue. Sci. Rep. 2018, 8, 1395. [CrossRef] [PubMed]

22. David, L.A.; Materna, A.C.; Friedman, J.; Campos-Baptista, M.I.; Blackburn, M.C.; Perrotta, A.; Erdman, S.E.; Alm, E.J. Host lifestyle affects human microbiota on daily timescales. Genome Biol. 2014, 15, R89. [CrossRef] [PubMed]

23. Gibson, G.R.; Roberfroid, M.B. Dietary modulation of the human colonic microbiota: Introducing the concept of prebiotics. J. Nutr. 1995, 125, 1401-1412. [CrossRef] [PubMed]

24. Valcheva, R.; Dieleman, L.A. Prebiotics: Definition and protective mechanisms. Best Pract. Res. Clin. Gastroenterol. 2016, 30, 27-37. [CrossRef] [PubMed] 
25. Hoving, L.R.; Katiraei, S.; Pronk, A.; Heijink, M.; Vonk, K.K.D.; Amghar-El Bouazzaoui, F.; Vermeulen, R.; Drinkwaard, L.; Giera, M.; van Harmelen, V.; et al. The prebiotic inulin modulates gut microbiota but does not ameliorate atherosclerosis in hypercholesterolemic apoe*3-leiden.Cetp mice. Sci. Rep. 2018, 8, 16515. [CrossRef] [PubMed]

26. Demigne, C.; Jacobs, H.; Moundras, C.; Davicco, M.J.; Horcajada, M.N.; Bernalier, A.; Coxam, V. Comparison of native or reformulated chicory fructans, or non-purified chicory, on rat cecal fermentation and mineral metabolism. Eur. J. Nutr. 2008, 47, 366-374. [CrossRef] [PubMed]

27. Hatori, M.; Vollmers, C.; Zarrinpar, A.; DiTacchio, L.; Bushong, E.A.; Gill, S.; Leblanc, M.; Chaix, A.; Joens, M.; Fitzpatrick, J.A.; et al. Time-restricted feeding without reducing caloric intake prevents metabolic diseases in mice fed a high-fat diet. Cell Metab. 2012, 15, 848-860. [CrossRef]

28. Wang, X.; Xue, J.; Yang, J.; Xie, M. Timed high-fat diet in the evening affects the hepatic circadian clock and pparalpha-mediated lipogenic gene expressions in mice. Genes Nutr. 2013, 8, 457-463. [CrossRef]

29. Arble, D.M.; Bass, J.; Laposky, A.D.; Vitaterna, M.H.; Turek, F.W. Circadian timing of food intake contributes to weight gain. Obesity 2009, 17, 2100-2102. [CrossRef]

30. Haraguchi, A.; Aoki, N.; Ohtsu, T.; Ikeda, Y.; Tahara, Y.; Shibata, S. Controlling access time to a high-fat diet during the inactive period protects against obesity in mice. Chronobiol. Int. 2014, 31, 935-944. [CrossRef]

31. Hsieh, S.D.; Muto, T.; Murase, T.; Tsuji, H.; Arase, Y. Association of short sleep duration with obesity, diabetes, fatty liver and behavioral factors in japanese men. Intern. Med. 2011, 50, 2499-2502. [CrossRef] [PubMed]

32. Baron, K.G.; Reid, K.J.; Kern, A.S.; Zee, P.C. Role of sleep timing in caloric intake and bmi. Obesity 2011, 19, 1374-1381. [CrossRef] [PubMed]

33. Oishi, K.; Konishi, T.; Hashimoto, C.; Yamamoto, S.; Takahashi, Y.; Shiina, Y. Dietary fish oil differentially ameliorates high-fructose diet-induced hepatic steatosis and hyperlipidemia in mice depending on time of feeding. J. Nutr. Biochem. 2018, 52, 45-53. [CrossRef] [PubMed]

34. Wada, T.; Ohguchi, M.; Iwai, Y. A novel enzyme of bacillus sp. 217c-11 that produces inulin from sucrose. Biosci. Biotechnol. Biochem. 2003, 67, 1327-1334. [CrossRef]

35. Wada, T.; Sugatani, J.; Terada, E.; Ohguchi, M.; Miwa, M. Physicochemical characterization and biological effects of inulin enzymatically synthesized from sucrose. J. Agric. Food Chem. 2005, 53, 1246-1253. [CrossRef]

36. Kowalski, T.J.; Farley, C.; Cohen-Williams, M.E.; Varty, G.; Spar, B.D. Melanin-concentrating hormone-1 receptor antagonism decreases feeding by reducing meal size. Eur. J. Pharmacol. 2004, 497, 41-47. [CrossRef]

37. Oh, J.; Lee, S.R.; Hwang, K.T.; Ji, G.E. The anti-obesity effects of the dietary combination of fermented red ginseng with levan in high fat diet mouse model. Phytother. Res. PTR 2014, 28, 617-622. [CrossRef]

38. Weitkunat, K.; Schumann, S.; Petzke, K.J.; Blaut, M.; Loh, G.; Klaus, S. Effects of dietary inulin on bacterial growth, short-chain fatty acid production and hepatic lipid metabolism in gnotobiotic mice. J. Nutr. Biochem. 2015, 26, 929-937. [CrossRef]

39. Ponziani, F.R.; Pecere, S.; Gasbarrini, A.; Ojetti, V. Physiology and pathophysiology of liver lipid metabolism. Expert Rev. Gastroenterol. Hepatol. 2015, 9, 1055-1067. [CrossRef]

40. Federico, A.; Dallio, M.; Di Sarno, R.; Giorgio, V.; Miele, L. Gut microbiota, obesity and metabolic disorders. Minerva Gastroenterol. E Dietol. 2017, 63, 337-344.

41. Pascale, A.; Marchesi, N.; Marelli, C.; Coppola, A.; Luzi, L.; Govoni, S.; Giustina, A.; Gazzaruso, C. Microbiota and metabolic diseases. Endocrine 2018, 61, 357-371. [CrossRef]

42. Huazano, A.; López, M.G. Metabolism of short chain fatty acids in colon and faeces of mice after a supplementation of diets with agave fructans. Lipid Metab. 2013, 8, 163-182.

43. Nishijima, S.; Suda, W.; Oshima, K.; Kim, S.W.; Hirose, Y.; Morita, H.; Hattori, M. The gut microbiome of healthy japanese and its microbial and functional uniqueness. DNA Res. Int. J. Rapid Publ. Rep. Genes Genomes 2016, 23, 125-133. [CrossRef]

44. Caporaso, J.G.; Kuczynski, J.; Stombaugh, J.; Bittinger, K.; Bushman, F.D.; Costello, E.K.; Fierer, N.; Pena, A.G.; Goodrich, J.K.; Gordon, J.I.; et al. Qiime allows analysis of high-throughput community sequencing data. Nat. Methods 2010, 7, 335-336. [CrossRef]

45. Edgar, R.C. Search and clustering orders of magnitude faster than blast. Bioinformatics 2010, 26, $2460-2461$. [CrossRef] 
46. Langille, M.G.; Zaneveld, J.; Caporaso, J.G.; McDonald, D.; Knights, D.; Reyes, J.A.; Clemente, J.C.; Burkepile, D.E.; Vega Thurber, R.L.; Knight, R.; et al. Predictive functional profiling of microbial communities using 16s rrna marker gene sequences. Nat. Biotechnol. 2013, 31, 814-821. [CrossRef]

47. Gibson, G.R.; Beatty, E.R.; Wang, X.; Cummings, J.H. Selective stimulation of bifidobacteria in the human colon by oligofructose and inulin. Gastroenterology 1995, 108, 975-982. [CrossRef]

48. Zhu, L.; Qin, S.; Zhai, S.; Gao, Y.; Li, L. Inulin with different degrees of polymerization modulates composition of intestinal microbiota in mice. FEMS Microbiol. Lett. 2017, 364, 364. [CrossRef]

49. Zhang, S.; Yang, J.; Henning, S.M.; Lee, R.; Hsu, M.; Grojean, E.; Pisegna, R.; Ly, A.; Heber, D.; Li, Z. Dietary pomegranate extract and inulin affect gut microbiome differentially in mice fed an obesogenic diet. Anaerobe 2017, 48, 184-193. [CrossRef]

50. Brighenti, F.; Casiraghi, M.C.; Canzi, E.; Ferrari, A. Effect of consumption of a ready-to-eat breakfast cereal containing inulin on the intestinal milieu and blood lipids in healthy male volunteers. Eur. J. Clin. Nutr. 1999, 53, 726-733. [CrossRef]

51. Takahashi, M.; Ozaki, M.; Kang, M.I.; Sasaki, H.; Fukazawa, M.; Iwakami, T.; Lim, P.J.; Kim, H.K.; Aoyama, S.; Shibata, S. Effects of meal timing on postprandial glucose metabolism and blood metabolites in healthy adults. Nutrients 2018, 10, 1763. [CrossRef]

52. Kuroda, H.; Tahara, Y.; Saito, K.; Ohnishi, N.; Kubo, Y.; Seo, Y.; Otsuka, M.; Fuse, Y.; Ohura, Y.; Hirao, A.; et al. Meal frequency patterns determine the phase of mouse peripheral circadian clocks. Sci. Rep. 2012, 2, 711. [CrossRef]

53. Hirao, A.; Nagahama, H.; Tsuboi, T.; Hirao, M.; Tahara, Y.; Shibata, S. Combination of starvation interval and food volume determines the phase of liver circadian rhythm in per2::Luc knock-in mice under two meals per day feeding. Am. J. Physiol. Gastrointest. Liver Physiol. 2010, 299, G1045-G1053. [CrossRef]

54. Ikeda, Y.; Sasaki, H.; Ohtsu, T.; Shiraishi, T.; Tahara, Y.; Shibata, S. Feeding and adrenal entrainment stimuli are both necessary for normal circadian oscillation of peripheral clocks in mice housed under different photoperiods. Chronobiol. Int. 2015, 32, 195-210. [CrossRef]

55. Sasaki, H.; Hattori, Y.; Ikeda, Y.; Kamagata, M.; Iwami, S.; Yasuda, S.; Shibata, S. Phase shifts in circadian peripheral clocks caused by exercise are dependent on the feeding schedule in per2::Luc mice. Chronobiol. Int. 2016, 33, 849-862. [CrossRef]

56. Sasaki, H.; Ohtsu, T.; Ikeda, Y.; Tsubosaka, M.; Shibata, S. Combination of meal and exercise timing with a high-fat diet influences energy expenditure and obesity in mice. Chronobiol. Int. 2014, 31, 959-975. [CrossRef]

57. Kilic, A.O.; Pavlova, S.I.; Ma, W.G.; Tao, L. Analysis of lactobacillus phages and bacteriocins in american dairy products and characterization of a phage isolated from yogurt. Appl. Environ. Microbiol. 1996, 62, 2111-2116.

58. Gilliland, S.E. Health and nutritional benefits from lactic acid bacteria. FEMS Microbiol. Rev. 1990, 7, 175-188. [CrossRef]

59. Koh, A.; Molinaro, A.; Stahlman, M.; Khan, M.T.; Schmidt, C.; Manneras-Holm, L.; Wu, H.; Carreras, A.; Jeong, H.; Olofsson, L.E.; et al. Microbially produced imidazole propionate impairs insulin signaling through mtorc1. Cell 2018, 175, 947-961.e917. [CrossRef]

60. Gomes, A.C.; Hoffmann, C.; Mota, J.F. The human gut microbiota: Metabolism and perspective in obesity. Gut Microbes 2018, 9, 308-325. [CrossRef]

61. Bervoets, L.; Van Hoorenbeeck, K.; Kortleven, I.; Van Noten, C.; Hens, N.; Vael, C.; Goossens, H.; Desager, K.N.; Vankerckhoven, V. Differences in gut microbiota composition between obese and lean children: A cross-sectional study. Gut Pathog. 2013, 5, 10. [CrossRef]

62. Delzenne, N.M.; Cani, P.D.; Neyrinck, A.M. Modulation of glucagon-like peptide 1 and energy metabolism by inulin and oligofructose: Experimental data. J. Nutr. 2007, 137, 2547s-2551s. [CrossRef]

63. Russo, F.; Chimienti, G.; Riezzo, G.; Pepe, G.; Petrosillo, G.; Chiloiro, M.; Marconi, E. Inulin-enriched pasta affects lipid profile and $\mathrm{lp}(\mathrm{a})$ concentrations in italian young healthy male volunteers. Eur. J. Nutr. 2008, 47, 453-459. [CrossRef]

64. Letexier, D.; Diraison, F.; Beylot, M. Addition of inulin to a moderately high-carbohydrate diet reduces hepatic lipogenesis and plasma triacylglycerol concentrations in humans. Am. J. Clin. Nutr. 2003, 77, 559-564. [CrossRef] 
65. Shirouchi, B.; Kawamura, S.; Matsuoka, R.; Baba, S.; Nagata, K.; Shiratake, S.; Tomoyori, H.; Imaizumi, K.; Sato, M. Dietary guar gum reduces lymph flow and diminishes lipid transport in thoracic duct-cannulated rats. Lipids 2011, 46, 789-793. [CrossRef]

66. Eastwood, M.A.; Morris, E.R. Physical properties of dietary fiber that influence physiological function: A model for polymers along the gastrointestinal tract. Am. J. Clin. Nutr. 1992, 55, 436-442. [CrossRef]

(C) 2019 by the authors. Licensee MDPI, Basel, Switzerland. This article is an open access article distributed under the terms and conditions of the Creative Commons Attribution (CC BY) license (http://creativecommons.org/licenses/by/4.0/). 